\title{
A Novel Integrated Topology to Interface Electric Vehicles and Renewable Energies with the Grid
}

\author{
Alfredo Alvarez-Diazcomas ${ }^{1,+}{ }^{\circledR}$, Héctor López ${ }^{1, \dagger}{ }^{,}$Roberto V. Carrillo-Serrano ${ }^{2,+}$ (i), \\ Juvenal Rodríguez-Reséndiz ${ }^{2, t, *(\mathbb{D})}$, Nimrod Vázquez ${ }^{1,+} \mathbb{D}$ and Gilberto Herrera-Ruiz ${ }^{2,+}$ \\ 1 Electronics Engineering Department, Instituto Tecnológico de Celaya, 38010 Celaya, Mexico; \\ m1703081@itcelaya.edu.mx (A.A.-D.); hector.lopez@itcelaya.edu.mx (H.L.); \\ nimrod.vazquez@itcelaya.edu.mx (N.V.) \\ 2 Facultad de Ingeniería, Universidad Autónoma de Querétaro, 76010 Queretaro, Mexico; \\ roberto.carrillo@uaq.mx (R.V.C.-S.); gherrera@uaq.mx (G.H.-R.) \\ * Correspondence: juvenal@uaq.edu.mx; Tel.: +52-442-192-1200 \\ + These authors contributed equally to this work.
}

Received: 19 September 2019; Accepted: 23 October 2019; Published: 26 October 2019

\begin{abstract}
Electric Vehicles (EVs) are an alternative to internal combustion engine cars to reduce the environmental impact of transportation. It is common to use several power sources to achieve the requirements of the electric motor. A proper power converter and an accurate control strategy need to be utilized to take advantage of the characteristics of every source. In this paper is presented a novel topology of a multiple-input bidirectional DC-DC power converter to interface two or more sources of energy with different voltage levels. Furthermore, it can be used as a buck or a boost in any of the possible conversion of energy. It is also possible to independently control the extracted power in each source and any combination of the elements of the system can be used as source and destiny for a transfer. Finally, the interaction with the grid is possible. The operation, analysis and design of the converter are presented with different modes of power transfer. Simulation results are shown where the theoretical analysis of the converter is validated.
\end{abstract}

Keywords: DC-DC/DC-AC power converter; electric vehicle; multi-input converter; sliding mode control; photovoltaic module; grid; renewable energies

\section{Introduction}

Global warming is one of the greatest challenges today for humankind. The transportation sector is one of the largest contributors to the emissions of greenhouse gases. It represents $27 \%$ in the European Union in 2016 and 28\% in the United States for the same year which represents the major contribution. Moreover, it is responsible for the greatest growth in emissions currently due to the growth of tourism, the globalized economy and the increase in living standards. A viable alternative to reduce emissions due to transportation is using electric vehicles (EVs), which practically behave like zero-emission cars [1].

In this type of cars, it is common to use several power sources to achieve the requirements of the electric motor such as fuel cells, batteries, ultracapacitors (UCs), and so forth. The aim of a hybrid energy storage system is to make use of the strong features of each source while eliminating their weaknesses [2]. Researchers have hybridized batteries and UCs in References [3-6] to create an ideal energy storage unit with high energy/power density, low cost/weight per unit capacity and a long cycle life. The battery can be used when the vehicle maintains a relatively constant velocity to take advantage of its high energy density characteristic. Also, the peak power transients during acceleration and regenerative braking can be avoided by the inclusion of a higher power density element such as an UC. The ability of the UC to handle higher power for a higher number of charge/discharge cycles 
not only increases the life span of the battery but also improves the overall system efficiency [7-9]. The active hybridization of the aforementioned energy storage system, in which the power/current in its output can be fully controlled, is only possible by means of utilizing power converters.

These converters can be isolated or non-isolated. In Reference [10] a novel multiport isolated bidirectional DC-DC converter for hybrid battery and supercapacitor applications is presented, which can achieve zero voltage switching for all switches in the whole load range. Moreover, the current ripples are greatly decreased by interleaved control, which is good for battery and supercapacitor. In Reference [11] it is proposed architecture eliminates two boost switches which are present in the two-stage counterpart. Moreover, the input inductors are operated in discontinuous conduction mode; thus, power can be shared between input sources through proper selection of input inductors. In Reference [12] a new modified LCLC series resonant circuit based dual-input single-output isolated converter is proposed for hybrid energy systems. With this novel converter topology, two different voltage sources can be decoupled completely and transfer the power from two separate dc sources to dc load simultaneously. Moreover, it consists of only two controllable switches for integrating two separate voltage sources; it can provide good voltage regulation and soft switching over a wide load range. Nevertheless, these converters use a transformer to achieve galvanic isolation between sources and output; therefore, are much more complex in terms of designing and control when compared to the non-isolated ones.

In References $[13,14]$ is presented a simple way to build a non-isolated hybrid energy storage system, connecting one of the sources directly while linking the other utilizing a DC-DC converter; yet this method does not permit the adjustment of the DC bus voltage. Another technique is to link each of the sources with the DC bus with an individual converter as presented in References [15-18]. In this way, it is possible to manage the DC bus voltage but it is an expensive solution due to the utilization of multiple converters. In order to decrease the cost, multiple-input converters have been proposed to achieve the goals of EVs. In Reference [19] is demonstrated that the multiple-input converters are cost effective, reliable, simple and easy to control. In Reference [20], energy flow between $N$ different sources and the DC link are discussed. In this topology, it is not possible to transfer energy directly between DC sources. In Reference [21] a Z-source converter for EV application is presented, although this topology is suitable for optimal devices and components, the number of voltage sources is limited to two and it is not possible to extend this topology for multiple-input sources. In Reference [22] a modular multipleinput converter is presented, whose input ports are connected to the DC bus via half-bridges. However, with this topology it is not possible to transfer the energy directly between the sources. In Reference [23] is presented a converter with the same characteristics as that presented in Reference [22] but with a reduced element count. In Reference [24] a flexible topology is presented that can be used as a boost or a buck in any transfer of the energy and allows the direct exchange of energy between the sources. A non-desirable characteristic of this converter is the presence of an inductor per input, due to the intrinsic weight of these elements. In Reference [25] a topology is introduced that presents a greater gain compared to other existing ones, for its use on fuel cell-based EVs. In detriment of this converter, it can be said that it is not bidirectional. In References [26] and [27] are proposed converters with multiple-input and multiple-output, utilizing only one inductor. These types of converters are very useful for its use with multilevel inverters. Nevertheless, are not bidirectional converters and that can be a limitation in this type of application. Moreover, in Reference [28] is presented an inverter for the injection of energy generated in a panel into the grid. As stated in Reference [29] it is very important to take advantage of the renewable energies and for that reason in this work the topology presented in Reference [28] was the base of the DC-DC converter proposed in order to achieve the interaction with the grid.

There are several solutions for converters to harvest the energy generated in a Photovoltaic module (PV) and store it in the battery.Reference [30] presents an isolated multiport bidirectional DC-DC converter capable of parallel power management of various renewable energy sources. The advantage of this converter is it utilizes less number of controllable switches and provides soft switching for 
converter primary switch. Reference [31] proposes a battery charger for an EV based on a Zeta converter. This converter has the advantage of an output current without ripple and it is possible to buck or boost the input voltage. On the other hand, in Reference [32] it is utilized a cascaded buck-boost converter for the application. Such converters are typical of PV-battery systems for its simplicity, its bidirectional capability and the versatility to buck or boost the input voltage. Another solution is presented in Reference [33] — a non-isolated three-port switching boost converter. By controlling three degrees of freedom, the ports have boost, buck and buck-boost characteristics. Nevertheless, as stated in Reference [34], the boost converters provide the lower cost and higher efficiency of the non-isolated converters for PV systems.

In order to minimize the size, weight and cost of the traditional on-board chargers, integrated chargers have been proposed, some topologies and techniques are reviewed in Reference [35]. One concept of integration was proposed by Rippel and Cocconi in References [36,37], consisting in the use of the existent inverter and motor windings for the charging operation. Since the traction operation and charging the battery are not simultaneous, using the drivetrain components could reduce the size and cost of the on-board chargers. This modified structure supports the charging/discharging process of the battery. Some examples based on an induction machine are presented in References [38-40], based on PMSMs in References [41,42], based on windings rearrangement in Reference [43] and finally based on multiphase machines in Reference [44]. Another technique consists of combining a modified DC-DC converter with the AC-DC bidirectional rectifier. In Reference [45] the integrated converter is able to function as an AC-DC battery charger and to transfer electrical energy between the battery pack and the high-voltage bus of the electric traction system. The converter has a reduced number of high-current inductors and current transducers and presents fault-current tolerance in PHEV conversion. In Reference [46] a single-stage integrated converter is proposed based on direct AC-DC conversion theory. The proposed converter eliminates the full-bridge rectifier, reduces the number of semiconductor switches and high current inductors and improves the conversion efficiency. In Reference [47] is presented a bidirectional converter that not only enables beneficial vehicle-to-grid (V2G) interactions but also ensures that all power delivered to and from the grid has good power factor and near zero current harmonics. To accomplish this task, a multi-level bidirectional AC-DC converter is combined with an integrated bidirectional DC-DC converter. The proposed converter has four different modes of operation that allows it to supply power to or from the battery to either the grid or the high voltage bus of the EV. As stated in Reference [48], the increase of the renewable energies can affect the power system efficacy, the power quality, the security, among other problems; therefore, these converters need to have the possibility of power factor correction (PFC) when charging the battery and low total harmonic distortion (THD) when injecting current into the grid to have an interaction with the grid without disturbing the quality of the energy.

The aim of this work is to propose an integrated topology that combines a multiple-input DC-DC converter and a bidirectional rectifier for the interaction of the storage devices with the grid. The proposed converter topology has all the considered advantages from the architectures presented in the literature, such as allowing the bidirectional power flow, the possibility of directly transferring the energy between sources, that for every transfer it is possible to boost or buck the input voltage, that any storage element of the system can be the source or destination for a transfer and has only one inductor, which means less weight, and finally, that it permits the interaction of the storage devices with the grid.

For this purpose, in the present investigation three main sources are considered-a PV, an UC and a battery. Furthermore, a pedal was thought to be mechanically connected to the engine to generate energy, through the electric machine when the vehicle is parked. In addition, when the automobile is in motion, it can help the engine with its mechanical load. All these elements can be seen in Figure 1, which shows a diagram of the considered EV. The focus of this paper is the DC-DC converter.

The operation and steady-state analysis of the proposed converter topology, with all its cases, is explained in Section 2. The size of the elements of the circuit is presented in Section 3. The control 
strategy used to regulate the converter is shown in Section 4. Finally, the simulation results for all cases are presented in Section 5.

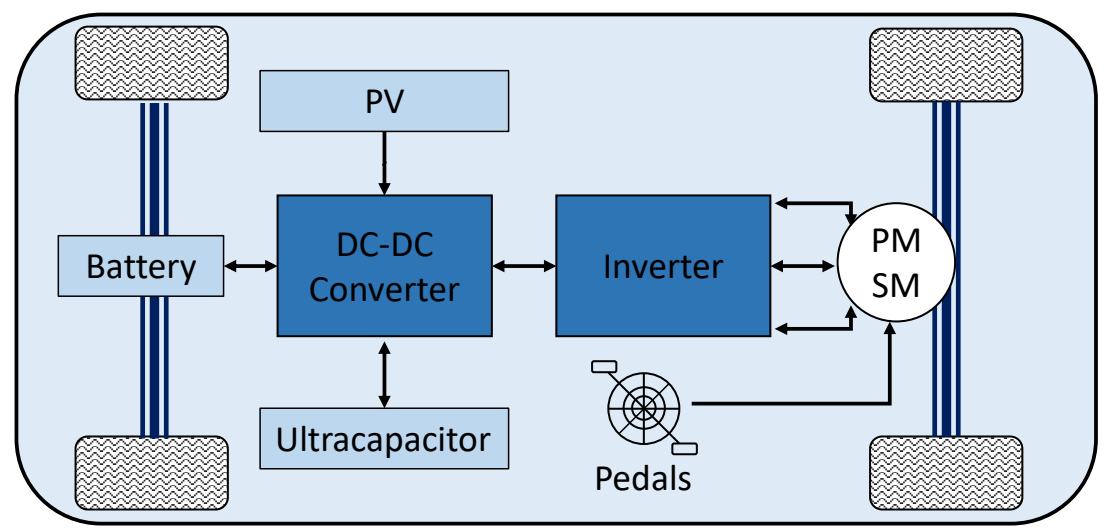

Figure 1. Diagram of the electric vehicle (EV) considered in this investigation.

\section{Operation and Analysis of the Converter}

The proposed power converter topology is displayed in Figure 2. It can be built by connecting each bidirectional source/output through two switches to the inductor $L_{2}$ while the unidirectional sources/outputs only need one switch. For a better understanding and analysis of the converter, this is divided into several stages in the present work. This can be done because they work independently. One of these stages is dedicated to the maximum power point tracking (MPPT) of the PV, shown in Figure 3. The other stage is the multiple-input converter shown in Figure 4. In case that an interaction with the grid is required to charge the UC or the battery, the diagram is shown in Figure 5. Furthermore, the injection of current into the grid was considered starting from the energy generated in the PV. In this way, when the vehicle is parked in daylight the energy can be harvested. Figure 6 indicates the circuit for this case. This article presents a detailed analysis of the operation of these converters, as well as simulation results for each of the possible cases.

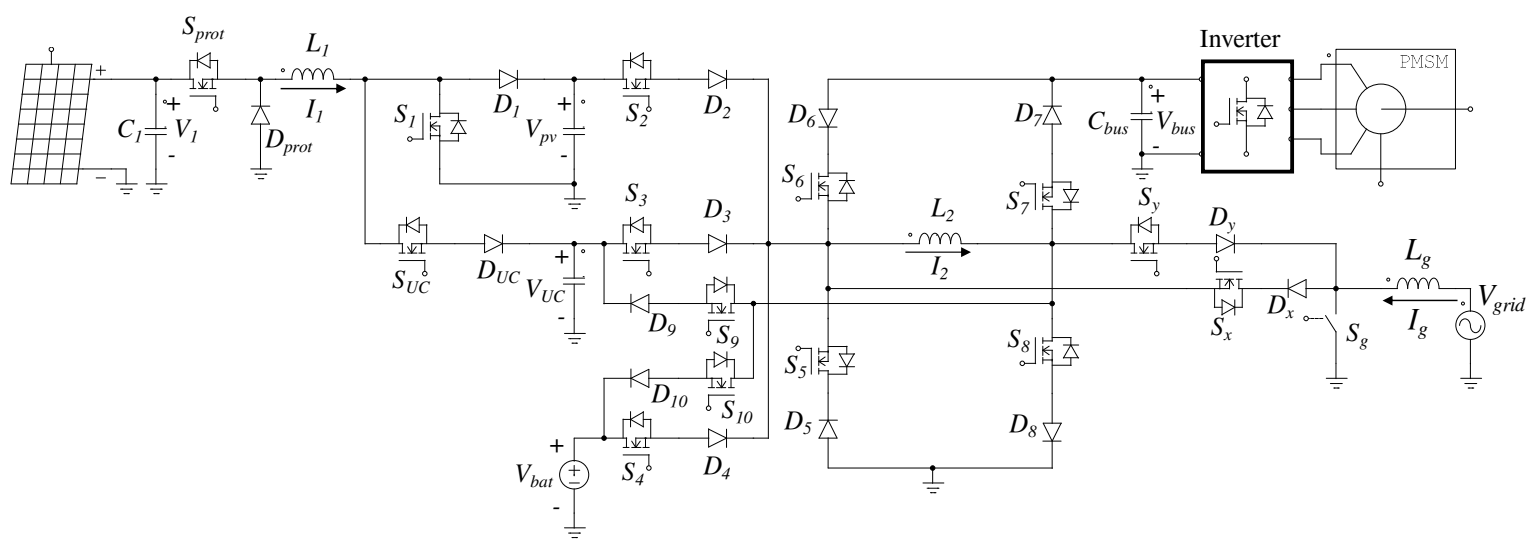

Figure 2. Proposed topology of the power converter. 


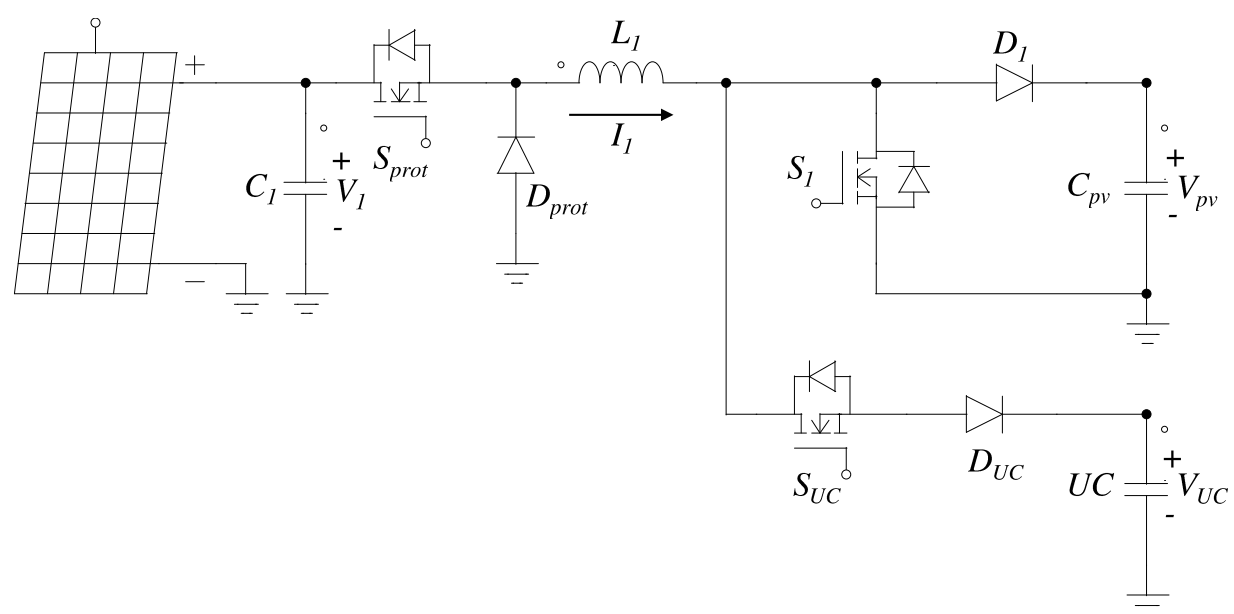

Figure 3. Converter associated with the PV.

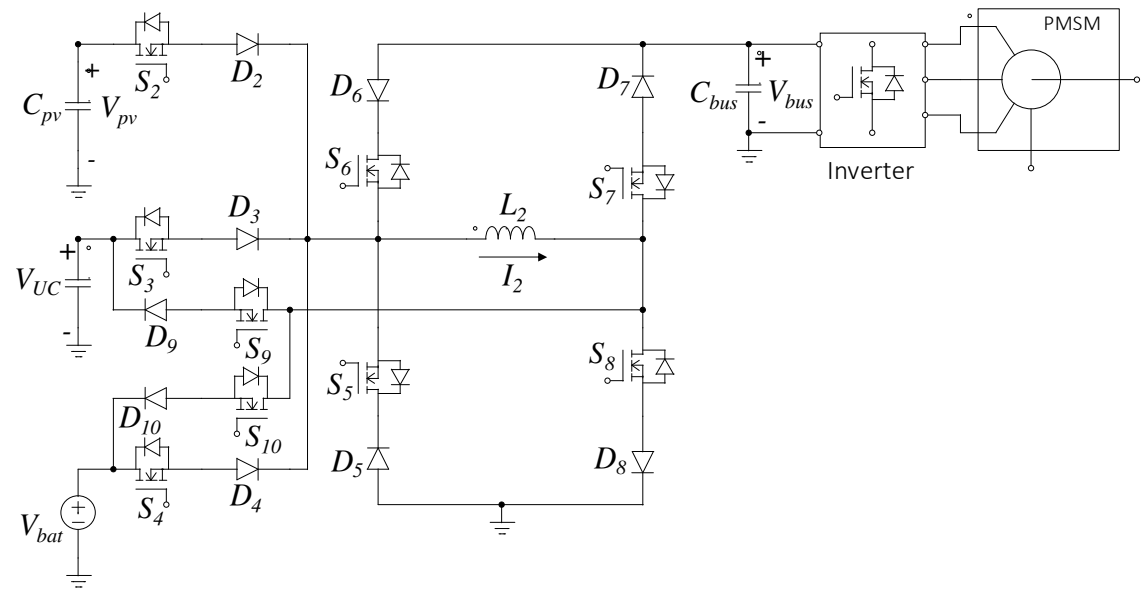

Figure 4. Multiple-input converter.

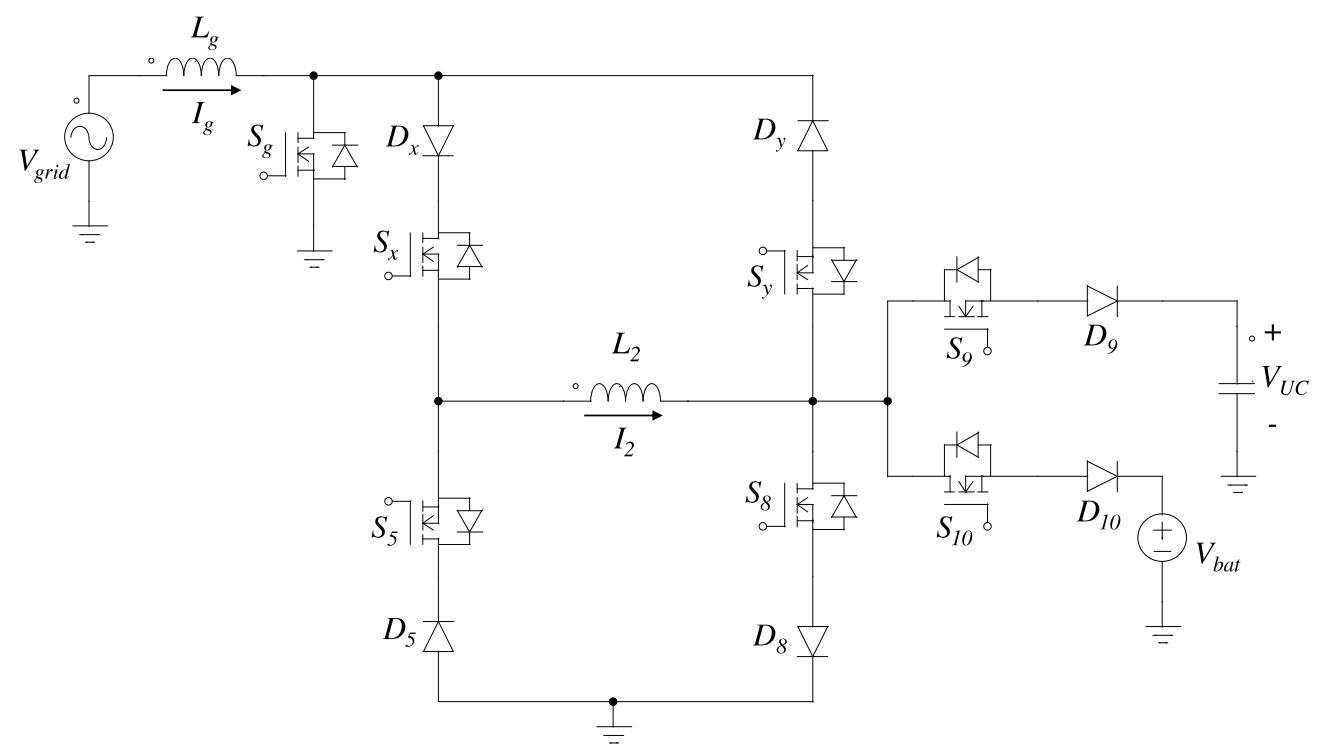

Figure 5. Circuit of the converter when it is needed the charge of the ultracapacitor (UC) or the battery. 


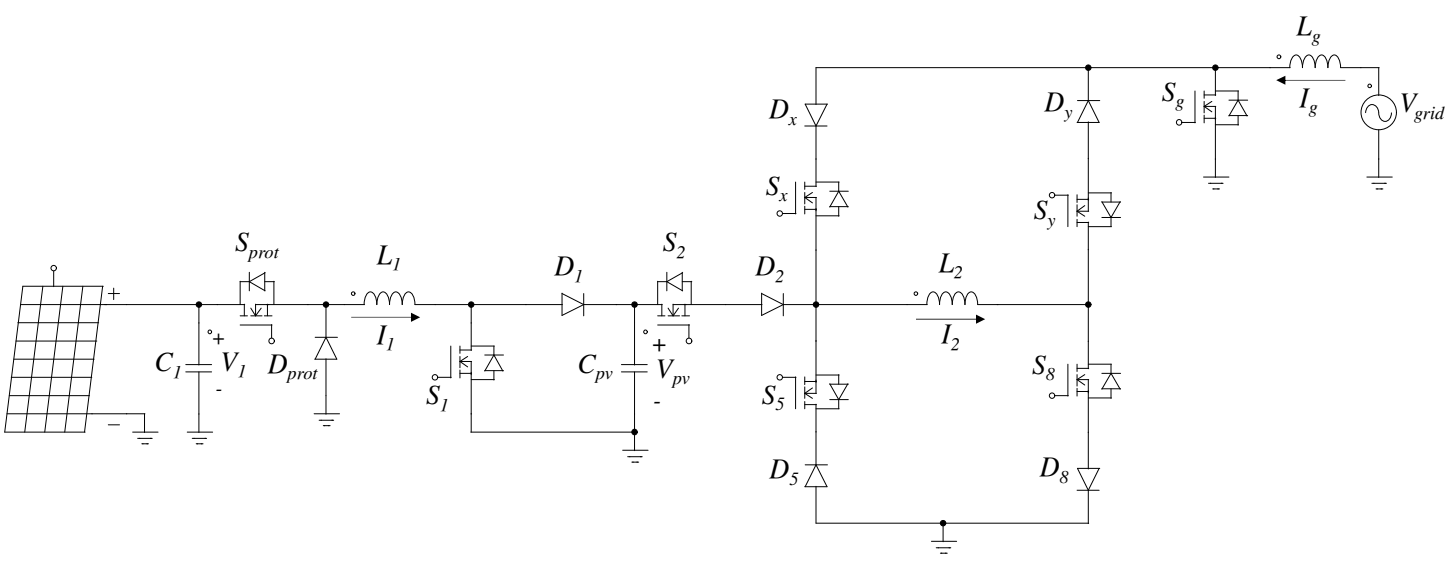

Figure 6. Circuit of the converter when the vehicle is parked in the sunlight.

In Table 1, various topologies are compared, attending several parameters of interest. Compared to the converters presented in the literature, the proposed topology presents more switches to its operation. Nevertheless, this is justified because it gathers all the advantages identified in the other converters.

Table 1. Comparison of the proposed converter with the existing ones.

\begin{tabular}{ccccccc}
\hline Topology & Bidirectional & $\begin{array}{c}\text { Transfer Directly } \\
\text { between Sources }\end{array}$ & $\begin{array}{c}\text { Extension } \\
\text { to } \\
\text { Multiport }\end{array}$ & $\begin{array}{c}\text { Operation in } \\
\text { Buck/Boost } \\
\text { Mode }\end{array}$ & $\begin{array}{c}\text { Interaction } \\
\text { with the } \\
\text { Grid }\end{array}$ & $\begin{array}{c}\text { Number of Devices } \\
\text { (n is Number } \\
\text { of Inputs) }\end{array}$ \\
\hline$[22]$ & Yes & No & Yes & No & No & $\begin{array}{c}\text { n inductors } \\
2 n \text { switches }\end{array}$ \\
\hline$[23]$ & Yes & No & Yes & No & No & $\begin{array}{c}\text { n inductors } \\
2+n \text { switches }\end{array}$ \\
\hline$[24]$ & Yes & Yes & Yes & Yes & No & $\begin{array}{c}\text { n inductors } \\
2 n+2 \text { switches }\end{array}$ \\
\hline$[25]$ & No & Yes & No & No & No & $\begin{array}{c}2 \text { inductors } \\
4 \text { switches }\end{array}$ \\
\hline $\begin{array}{c}\text { Proposed } \\
\text { converter }\end{array}$ & Yes & Yes & Yes & Yes & Yes & $\begin{array}{c}1 \text { inductor } \\
2 \mathrm{n}+4 \text { switches }\end{array}$ \\
\hline
\end{tabular}

Now, the converter associated with the PV will be analyzed. When it is dedicated a converter to achieve the MPPT it is easiest to control the system. Some modifications were done to the boost converter such as the addition of the elements $S_{\text {prot }}$ and $D_{\text {prot }}$ for the protection of the system. It allows to isolate the PV in case no more energy is required without damaging the inductor $L_{1}$. Finally, the $S_{U C}$ switch is added to provide greater versatility to the circuit.

In order to make better use of the energy the UC voltage is monitored to define the switch on which to act. In case that the $V_{U C}>V_{1}$ the energy of the PV is transferred to the UC and the capacitor $C_{p v}$. Switch $S_{1}$ is first turned on and the voltage $V_{1}$ appears across $L_{1}$, resulting in the increase of the current in this device with a slope of $V_{1} / L_{1}$. In the next interval, this switch is turned off and switch $S_{U C}$ and diode $D_{1}$ are turned on. In this way, the energy stored in the inductor is transferred to the UC and the capacitor $C_{p v}$. It was decided to not include a switch in the position of the diode $D_{1}$ because it is acceptable for the application that the voltage in capacitor $C_{p v}$ matches the voltage in the UC. Figure 7 shows the two stages needed to achieve the transfer of the energy. 


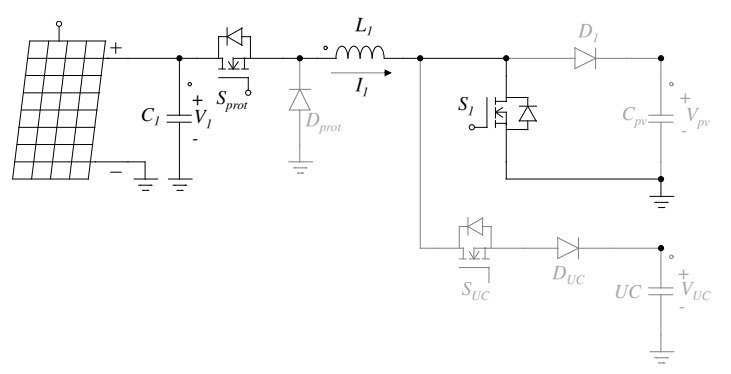

(a)

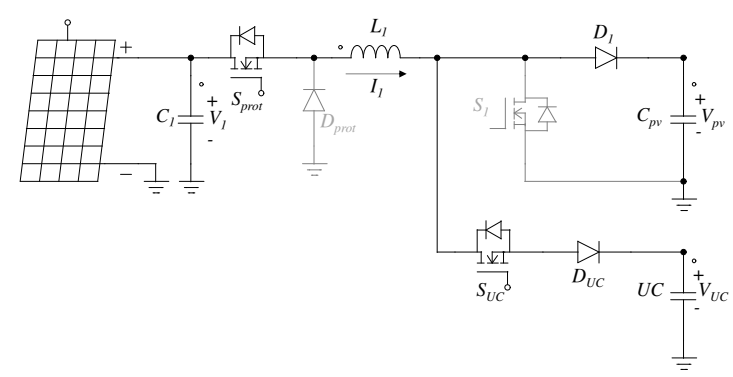

(b)

Figure 7. Operating modes of the converter associated with the PV when $V_{U C}>V_{1}$, (a) charge of the inductor, (b) discharge of the inductor.

In Table 2 are represented the operating modes of the converter associated with the PV. If $V_{1}>V_{U C}$, the inductor is charged through the $S_{U C}$ switch in order to emulate the behavior of the boost converter. In both cases, the point of operation in steady-state is giving by Equation (1). It is necessary to point out that in case that $V_{U C}$ is greater than $V_{1}$, then $V_{p v}=V_{U C}$.

$$
V_{p v}=\frac{1}{1-D} V_{1}
$$

where $D$ is the duty cycle giving by Equation (2).

$$
D=\frac{t_{1 A}}{t_{1 A}+t_{1 B}}
$$

where $t_{1 A}$ is the length of time of the mode $1 A$ of Table 2 and $t_{1 B}$ is the length of time of the mode $1 B$ of Table 2 .

Table 2. Operating modes of the converter associated with the PV.

\begin{tabular}{ccccccc}
\hline Transfer & $V_{U C}>V_{\mathbf{1}}$ & Mode & Switches on & $\boldsymbol{L}_{\mathbf{1}}$ & $C_{\boldsymbol{p v}}$ & $\mathrm{UC}$ \\
\hline \multirow{2}{*}{$1 . \mathrm{PV} \rightarrow C_{p v}, \mathrm{UC}$} & Yes & $1 A$ & $S_{1}$ & ${ }^{a}$ & $={ }^{b}$ & $=$ \\
& & $1 B$ & $S_{U C}, D_{1}$ & $-{ }^{c}$ & + & + \\
$2 . \mathrm{PV} \rightarrow C_{p v}, \mathrm{UC}$ & \multirow{2}{*}{ No } & $2 A$ & $S_{U C}$ & + & $=$ & + \\
& & $2 B$ & $D_{1}$ & - & + & $=$ \\
\hline
\end{tabular}

${ }^{a}$ Increase the state of charge; ${ }^{b}$ The same state of charge was kept; ${ }^{c}$ Decrease the state of charge.

Now, the multiple-input converter will be analyzed. The operating modes used in the multiple-input converter emulates the behavior of a buck converter or a boost one. Figure 8 shows the operating modes for a transfer from the battery to the capacitor $C_{b u s}$. Switches $S_{4}$ and $S_{8}$ are first turned on and the voltage $V_{b a t}$ appear across inductor $L_{2}$, resulting in the increase of the current in this device with a slope of $V_{b a t} / L_{2}$. In the next interval, switch $S_{8}$ is turned off and switch $S_{7}$ is turned on to complete the transfer of energy to the bus. Therefore, $S_{4}$ stay on throughout the transfer and switches $S_{7}$ and $S_{8}$ work in a complementary manner. As mentioned before, the proposed converter is very flexible, allowing that any element of the system can be source or destiny for a transfer and any transfer can be performed by boosting or reducing the input voltage. Hence, the aforementioned transfer can be realized reducing the input voltage with the correct combination of switches. Nevertheless, for this application, only the transfers present in Table 3 were considered.

One of the main concerns when using the number of switches utilized is the efficiency of the system. However, this is not a serious problem since only three switches are used to perform a transfer of energy; one that stays on and two that work in a complementary way, as can be appreciated in Table 3. 


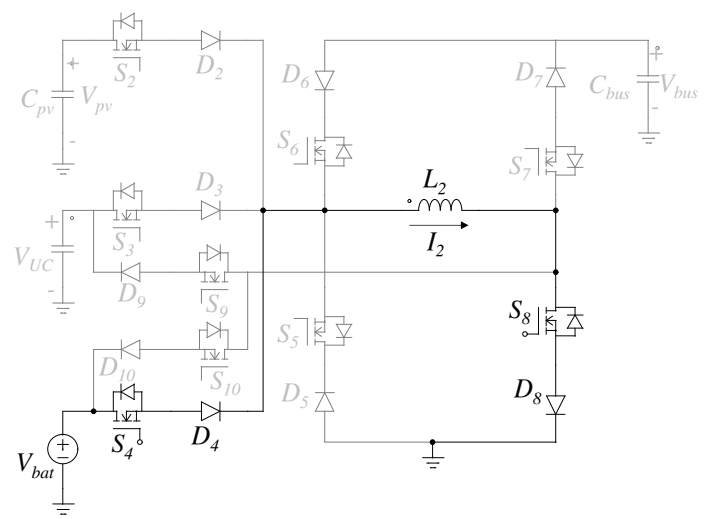

(a)

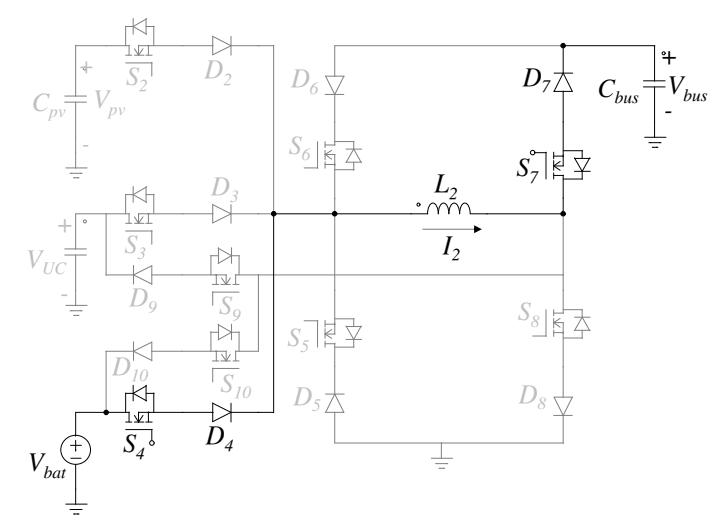

(b)

Figure 8. Operating modes of the multiple-input converter, (a) charge of the inductor, (b) discharge of the inductor.

Table 3. Operating modes of the multiple-input converter.

\begin{tabular}{|c|c|c|c|c|c|c|c|c|c|}
\hline Transfer & Behavior & Mode & Switches on & $L_{2}$ & $C_{p v}$ & UC & Bat & Bus & Steady-State \\
\hline \multirow{2}{*}{ 3. Bat $\rightarrow$ Bus } & \multirow{2}{*}{ Boost } & $3 A$ & $S_{4}, S_{8}$ & + & $=$ & $=$ & - & $=$ & \multirow{2}{*}{$V_{b u s}=\frac{1}{1-D} V_{b a t}$} \\
\hline & & $3 B$ & $S_{4}, S_{7}$ & - & $=$ & $=$ & - & + & \\
\hline \multirow{2}{*}{ 4. UC $\rightarrow$ Bus } & \multirow{2}{*}{ Boost } & $4 A$ & $S_{3}, S_{8}$ & + & $=$ & - & $=$ & $=$ & \multirow{2}{*}{$V_{b u s}=\frac{1}{1-D} V_{U C}$} \\
\hline & & $4 B$ & $S_{3}, S_{7}$ & - & $=$ & - & $=$ & + & \\
\hline \multirow{2}{*}{ 5. $\mathrm{PV} \rightarrow$ Bus } & \multirow{2}{*}{ Boost } & $5 A$ & $S_{2}, S_{8}$ & + & - & $=$ & $=$ & $=$ & \multirow{2}{*}{$V_{b u s}=\frac{1}{1-D} V_{p v}$} \\
\hline & & $5 B$ & $S_{2}, S_{7}$ & - & - & $=$ & $=$ & + & \\
\hline \multirow{2}{*}{ 6. $\mathrm{PV} \rightarrow \mathrm{UC}$} & \multirow{2}{*}{ Boost } & $6 A$ & $S_{2}, S_{8}$ & + & - & $=$ & $=$ & $=$ & \multirow{2}{*}{$V_{U C}=\frac{1}{1-D} V_{p v}$} \\
\hline & & $6 B$ & $S_{2}, S_{9}$ & - & - & + & $=$ & $=$ & \\
\hline \multirow{2}{*}{ 7. PV $\rightarrow$ Bat } & \multirow{2}{*}{ Boost } & $7 A$ & $S_{2}, S_{8}$ & + & - & $=$ & $=$ & $=$ & \multirow{2}{*}{$V_{b a t}=\frac{1}{1-D} V_{p v}$} \\
\hline & & $7 B$ & $S_{2}, S_{10}$ & - & - & $=$ & + & $=$ & \\
\hline \multirow{2}{*}{ 8. Bat $\rightarrow \mathrm{UC}$} & \multirow{2}{*}{ Buck } & $8 A$ & $S_{4}, S_{9}$ & + & $=$ & + & - & $=$ & \multirow{2}{*}{$V_{U C}=D V_{b a t}$} \\
\hline & & $8 B$ & $S_{5}, S_{9}$ & - & $=$ & + & $=$ & $=$ & \\
\hline \multirow{2}{*}{ 9. Bus $\rightarrow$ Bat } & \multirow{2}{*}{ Buck } & $9 A$ & $S_{6}, S_{10}$ & + & $=$ & $=$ & $=$ & - & \multirow{2}{*}{$V_{b a t}=D V_{b u s}$} \\
\hline & & $9 B$ & $S_{5}, S_{10}$ & - & $=$ & $=$ & + & $=$ & \\
\hline \multirow{2}{*}{ 10. Bus $\rightarrow \mathrm{UC}$} & \multirow{2}{*}{ Buck } & $10 A$ & $S_{6}, S_{9}$ & + & $=$ & + & $=$ & - & \multirow{2}{*}{$V_{U C}=D V_{b u s}$} \\
\hline & & $10 B$ & $S_{5}, S_{9}$ & - & $=$ & + & $=$ & $=$ & \\
\hline
\end{tabular}

The losses analysis of the proposed topology can be done with the circuit presented in Figure 9. The power dissipated by the devices $S_{4}, D_{4}$ and $L_{2}$ is mainly by means of conduction due to the current is flowing in these devices at all time and is given by the Equation (3). The conduction power loss of the switches $S_{7}$ and $S_{8}$ are given by the Equation (4), while the switching power loss is given by Equation (5). Finally, total power dissipation due to all the elements is given by the Equation (6). Where $I_{2}$ is the current through the inductor $L_{2}, D$ is the duty cycle, $f_{s w}$ is the switching frequency, $t_{r}$ is the rise time of the Metal-Oxide-Semiconductor Field-effect Transistors (MOSFETs), $t_{f}$ is the fall time of the MOSFETs and $R_{S L}, R_{D S(o n) S 4}, R_{D S(o n) D 4}, R_{D S(o n) S 8}, R_{D S(o n) D 8}, R_{D S(o n) S 7}, R_{D S(o n) D 7}$ are the series resistance of the inductor $L_{2}$, switch $S_{4}$, diode $D_{4}$, switch $S_{8}$, diode $D_{8}$, switch $S_{7}$ and diode $D_{7}$ respectively. From this analysis, it can be appreciated that it is not a major issue the power loss compared to topologies that exist in the literature and the use of all the switches can be justified by the advantages gathered in the proposed topology.

$$
P_{L_{1}}=I_{2}^{2}\left(R_{S L}+R_{D S(o n) S 4}+R_{D S(o n) D 4}\right)
$$


$P_{L_{2}}=I_{2}^{2} D\left(R_{D S(o n) S 8}+R_{D S(o n) D 8}\right)+I_{2}^{2}(1-D)\left(R_{D S(o n) S 7}+R_{D S(o n) D 7}\right)$

$$
P_{L_{3}}=V_{i n} I_{2} f_{s w}\left(t_{r}+t_{f}\right)
$$

$$
P_{L_{-} \text {Total }}=P_{L_{1}}+P_{L_{2}}+P_{L_{3}}
$$

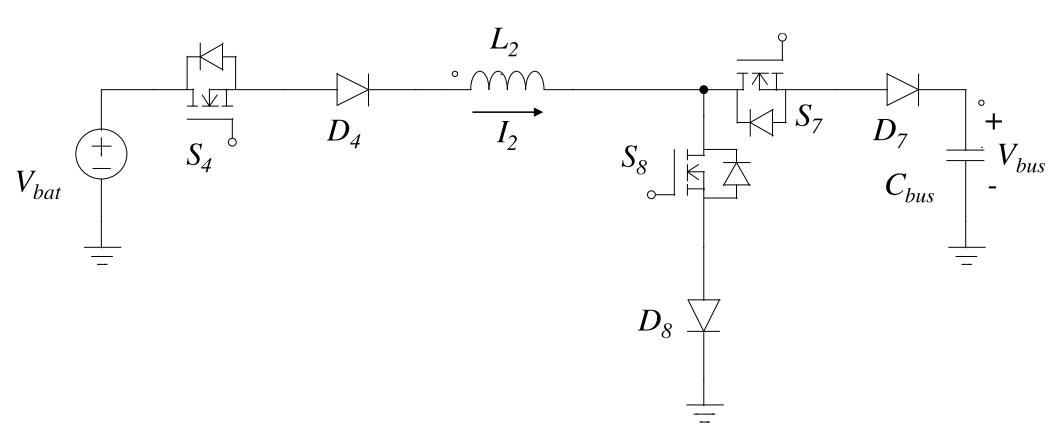

Figure 9. Circuit considered for the analysis of the losses.

For the efficiency calculation it can be assumed that the on-resistance of the MOSFETs and diodes is of $0.5 \Omega$, a rise time $\left(t_{r}\right)$ of $28 n s$ and a decrease time $\left(t_{f}\right)$ of $44 n s$. Finally, the series resistance of the inductor is estimated to $1 \Omega$. The transfer that causes a greater loss is from UC to the bus and for that reason this conversion was considered for the power loss calculation. In this conversion the current through $I_{2}$ is of $10 \mathrm{~A}$ and the voltage in the UC is of $125 \mathrm{~V}$. Substituting the corresponding values in Equations (3)-(6) it is obtained that the total power loss is of $309 \mathrm{~V}$. The efficiency is given by Equation (7), which for an output power of $1.8 \mathrm{~kW}$ the efficiency is of $85.35 \%$.

$$
\eta=\frac{P_{O}}{P_{O}+P_{L_{-} \text {Total }}} 100
$$

\section{Design of the Converter}

In this section, the analysis for the sizing of the inductors $L_{1}$ and $L_{2}$ will be explained, as well as the capacitors $C_{p v}$ and $C_{b u s}$. First, the calculation of the components associated with the PV converter were performed. For the calculation of these elements, the methodology described in Reference [49] was followed. In this way, the capacitor was calculated as described in Equation (8), while the inductor was obtained as set out in Equation (9).

$$
\begin{gathered}
C_{p v}=\frac{D P_{O}}{V_{O} \Delta V_{O} f} \\
L_{1}=\frac{D(1-D)^{2} V_{O}^{2}}{2 f P_{O}}
\end{gathered}
$$

where $D$ is the duty cycle, $P_{O}$ is the output power, $V_{O}$ is the output voltage and $f$ is the switching frequency.

To make the calculation was necessary to take into account some design considerations with respect to the PV and the desired operation for the converter. In this application was considered a PV that has an open circuit voltage of $50 \mathrm{~V}$, short circuit current of $10 \mathrm{~A}$ and with a maximum power point of energy transfer around $25 \mathrm{~V}$ and $4-5 \mathrm{~A}(100-125 \mathrm{~W})$. As proposed in [31], a $D=0.5$ is used, the switching frequency was set in $50 \mathrm{kHz}$, while the typical output power was fixed in $150 \mathrm{~W}$. Finally, the variation in the output voltage was defined as $10 \mathrm{~V}$. For this data, the capacitor value needs to be greater than $3 \mu \mathrm{F}$. Finally, the inductor value was calculated and determined as $21 \mu \mathrm{H}$. 
Next, the values of the inductor and the capacitor of the multiple-input converter were calculated. As explained in the previous section, this converter always behaves as a buck or as a boost. For this reason, the strategy followed to obtain these parameters was to calculate the necessary values for each case and take the critical values. The equations used to dimension the power elements in a buck converter are described in Reference [50] and are presented in (10) and (11). While the equations used for the sizing of the power elements in a boost converter are described in Reference [51] and are presented in (12) and (13).

$$
\begin{gathered}
C=\frac{\Delta I_{L}}{8 f \Delta V_{O}} \\
L=\frac{V_{O}\left(V_{\text {in }}-V_{O}\right)}{\Delta I_{L} f V_{\text {in }}} \\
C=\frac{I_{O} D}{f \Delta V_{O}} \\
L=\frac{V_{\text {in }}\left(V_{O}-V_{\text {in }}\right)}{\Delta I_{L} f V_{O}}
\end{gathered}
$$

where $I_{L}$ is the current through the inductor, $f$ is the switching frequency, $V_{O}$ is the output voltage, $V_{\text {in }}$ is the input voltage, $I_{O}$ is the output current and $D$ is the duty cycle.

Taking into account these equations, and the behavior that was highlighted in the previous section for each state, Table 4 was constructed. In this table are presented the nominal values of the parameters needed for the sizing of the power elements. In this way, was possible to calculate the minimum inductance and capacitance allowable for the proper operation of the converter. It is important to highlight that the transfers concerning the PV were not included because this source of energy is considered as auxiliary. It can be concluded after analyzing this table that the value needed for the inductor $L_{2}$ must be higher than $3.86 \mathrm{mH}$ and for the capacitor $C_{b u s}$ it must be greater than $144 \mu \mathrm{F}$.

Table 4. Sizing of the power elements of the multiple-input converter.

\begin{tabular}{ccccccccccc}
\hline Transfer & Behavior & $V_{\boldsymbol{O}}[\mathrm{V}]$ & $V_{\boldsymbol{i n}}[\mathrm{V}]$ & $\Delta \boldsymbol{I}_{\boldsymbol{L}}[\mathrm{A}]$ & $\Delta \boldsymbol{V}_{\boldsymbol{O}}[\mathrm{V}]$ & $\boldsymbol{I}_{\boldsymbol{O}}[\mathrm{A}]$ & $\boldsymbol{D}$ & $f[\mathrm{kHz}]$ & $\boldsymbol{L}_{2}[\mathrm{mH}]$ & $C_{\text {bus }}[\mu \mathrm{F}]$ \\
\hline 3. Bat $\rightarrow$ Bus & Boost & 450 & 140 & 0.5 & 1 & 10 & 0.69 & 50 & 3.86 & 138 \\
4. UC $\rightarrow$ Bus & Boost & 450 & 125 & 0.5 & 1 & 10 & 0.72 & 50 & 3.61 & $\mathbf{1 4 4}$ \\
8. Bat $\rightarrow \mathrm{UC}$ & Buck & 125 & 140 & 1 & - & - & - & 50 & 0.27 & - \\
9. Bus $\rightarrow$ Bat & Buck & 140 & 450 & 1 & - & - & - & 50 & 1.93 & - \\
10. Bus $\rightarrow \mathrm{UC}$ & Buck & 125 & 450 & 1 & - & - & - & 50 & 1.81 & - \\
\hline
\end{tabular}

\section{Control Strategy}

The control diagram of the system is shown in Figure 10.

It can be appreciated that there are several levels of hierarchy. The purpose of the lower level is to achieve the regulation of the state variables of the converter. Moreover, are present the blocks of MPPT, which are responsible for the extraction of the maximum power. Finally, there is an energy management system (EMS) that dictates the proper transfer at every moment. There are several strategies to control the state variables in a switching power converter as the ones presented in Reference [52]. Nevertheless, in this work, the current through $L_{2}$ was regulated utilizing a sliding mode control (SMC) because this technique is naturally suited for the regulation of switched controlled systems such as DC-DC power converters [53] and for its robustness, as stated in References [54-56]. Moreover, the control parameter can be the same to regulate the current in a boost and a buck converter as demonstrated in Table 5. In this table, $V_{i n}, v_{C}$ and $i_{L}$ are the variables of the respective converter, while $u$ is the input signal (for this case is the state of the switch), $\sigma$ is the sliding surface and $S$ is the control parameter of the SMC. 


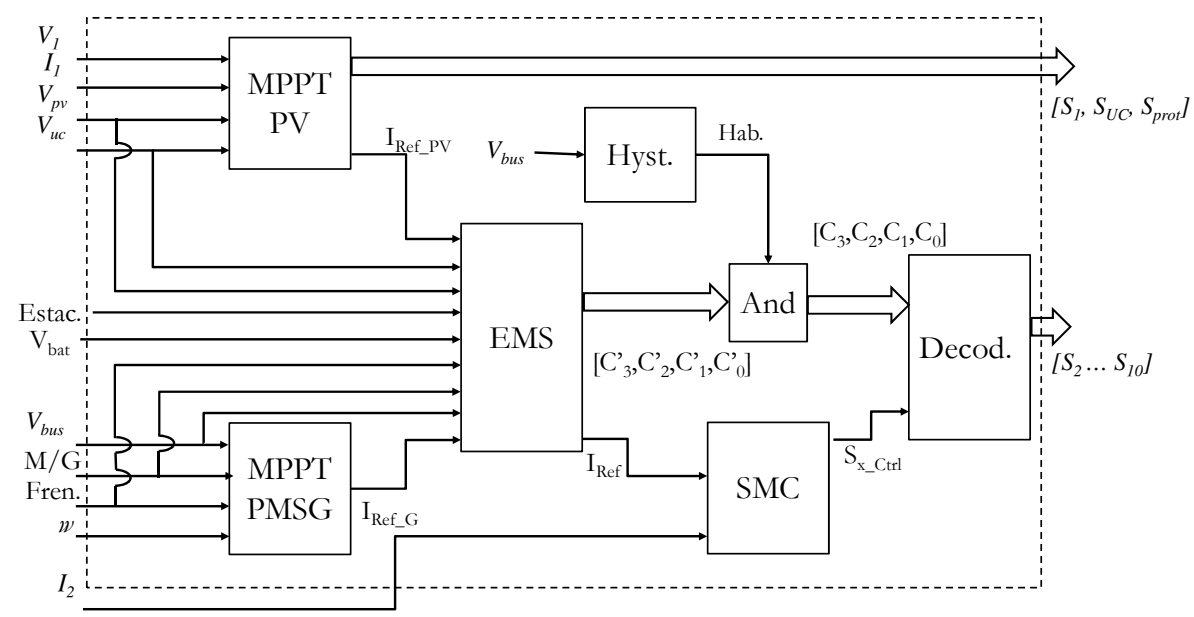

Figure 10. Block diagram of the controller of the system.

Table 5. Demonstration of the homogeneity of the control parameter for the regulation of the current with SMC in a buck and a boost converter.

\begin{tabular}{|c|c|c|}
\hline Action & Buck Converter & Boost Converter \\
\hline Model Obtention & {$\left[\begin{array}{c}\dot{i_{L}} \\
v_{C}\end{array}\right]=\left[\begin{array}{cc}0 & -\frac{1}{L} \\
\frac{1}{C} & -\frac{1}{R C}\end{array}\right]\left[\begin{array}{c}i_{L} \\
v_{C}\end{array}\right]+\left[\begin{array}{c}u \\
L \\
0\end{array}\right] V_{i n}$} & {$\left[\begin{array}{c}\dot{i_{L}} \\
v_{C}\end{array}\right]=\left[\begin{array}{cc}0 & \frac{u-1}{L_{1}} \\
\frac{1-u}{C} & -\frac{1}{R C}\end{array}\right]\left[\begin{array}{l}i_{L} \\
v_{C}\end{array}\right]+\left[\begin{array}{l}1 \\
L \\
0\end{array}\right] V_{i n}$} \\
\hline $\begin{array}{l}\text { Proposing the sliding } \\
\text { surface }\end{array}$ & $\begin{array}{c}\sigma=S\left(i_{L}-i_{R E F}\right) \\
u=\left(\begin{array}{ccc}1 & \text { si } & \sigma<0 \\
0 & \text { si } & \sigma>0\end{array}\right)\end{array}$ & $\begin{array}{c}\sigma=S\left(i_{L}-i_{R E F}\right) \\
u=\left(\begin{array}{lll}1 & \text { si } & \sigma<0 \\
0 & \text { si } & \sigma>0\end{array}\right)\end{array}$ \\
\hline $\begin{array}{l}\text { Obtaining the } \\
\text { derivative of the } \\
\text { sliding surface }\end{array}$ & $\dot{\sigma}=S\left(-\frac{v_{C}}{L}+\frac{u V_{i n}}{L}\right)$ & $\dot{\sigma}=S\left(\frac{(u-1) v_{C}}{L}+\frac{V_{i n}}{L}\right)$ \\
\hline $\begin{array}{l}\text { Verify the existence } \\
\text { condition }(\sigma>0)\end{array}$ & $\dot{\sigma}=S\left(-\frac{v_{C}}{L}\right)=S *$ Negative number & $\dot{\sigma}=S\left(\frac{V_{i n}-v_{C}}{L}\right)=S *$ Negative number \\
\hline $\begin{array}{l}\text { Verify the existence } \\
\text { condition }(\sigma<0)\end{array}$ & $\dot{\sigma}=S\left(\frac{V_{\text {in }}-v_{C}}{L}\right)=S *$ Positive number & $\dot{\sigma}=S\left(\frac{V_{i n}}{L}\right)=S *$ Positive number \\
\hline $\begin{array}{l}\text { Define the sign of the } \\
\text { parameter } S(\sigma \dot{\sigma}<0)\end{array}$ & $S$ must be positive & $S$ must be positive \\
\hline
\end{tabular}

The other state variable is the bus voltage $\left(V_{b u s}\right)$. This voltage was regulated with an on-off controller, because it is not necessarily an exact value in the input of the inverter and because of its simplicity. The range of the voltage was defined from $400 \mathrm{~V}$ to $500 \mathrm{~V}$. This controller enable/disable the input current to the capacitor $C_{b u s}$.

In order to achieve the MPPT of the PMSG there are several techniques like that presented in Reference [57] and is used in this work due to its simplicity. This algorithm is based on the principle that if the voltage in the capacitor $C_{b u s}$ is kept constant, then the maximum possible energy is being extracted. On the other hand, the MPPT applied for the PV was based on a Perturb and Observe (P\&O) algorithm. This algorithm was implemented with the PV as the active input in the multiple-input converter and manipulating the current through the inductor $L_{2}$. Nevertheless, this is not always possible as the multiple-input converter can be needed for other functions. If this were the case, then the algorithm manipulates the state of the switches $S_{U C}$ and $S_{1}$.

Finally, the EMS is the element that establishes the proper transfer in every moment. It is based on if-else rules to achieve its purpose. Figure 11 shows the main cases treated in this controller. If the vehicle is parked, then the source generating energy transfer is the same as the storage device that needs it. In this case, the UC is prioritized because it is desirable that the demanded energy at the start of the motion was supplied by this device. If the vehicle is in motion with positive acceleration 
and there is energy in both power sources, the flowchart depicted in Figure 12 is followed. If, on the contrary, there is only one power source with energy, then this device supplies the power during the driving cycle. Lastly, when the vehicle is in regenerative braking the energy generated is stored in the capacitor $C_{b u s}$. For each case, the EMS establishes a code and the output decoder with this information and the control signal from the SMC sends the correct signal for each switch.

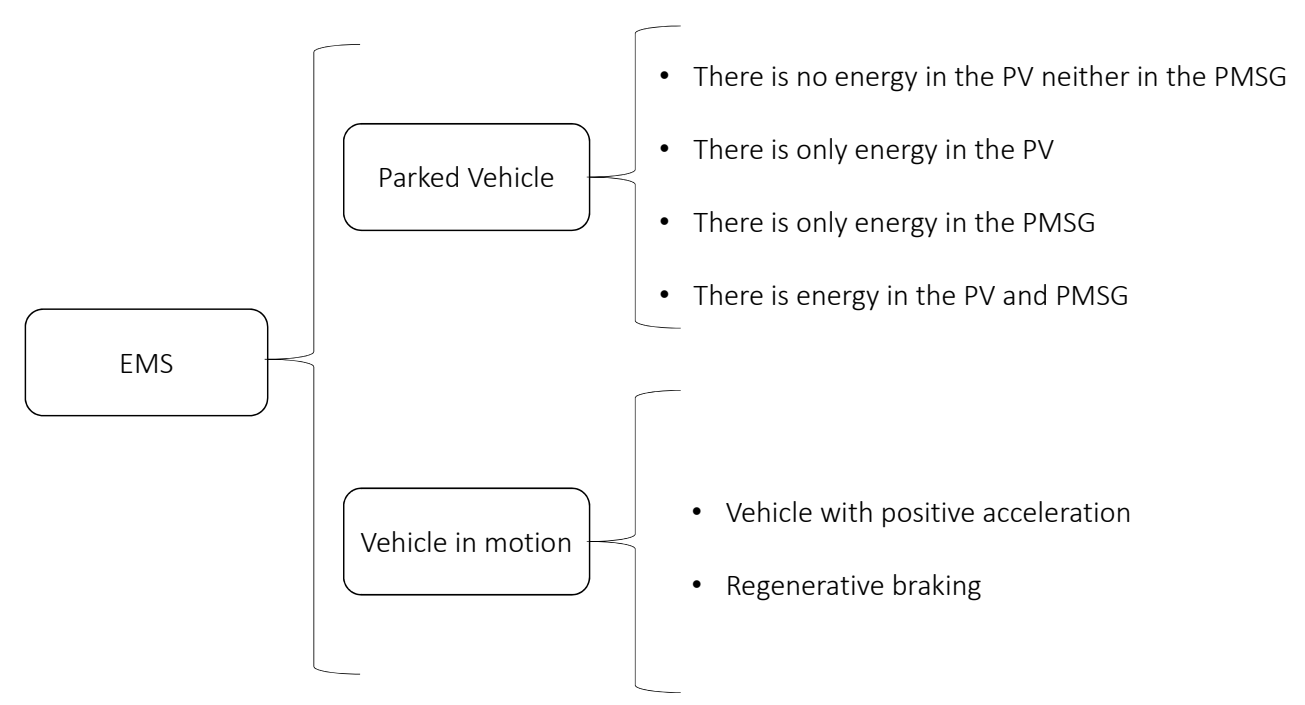

Figure 11. Cases taking into account for the implementation of the EMS.

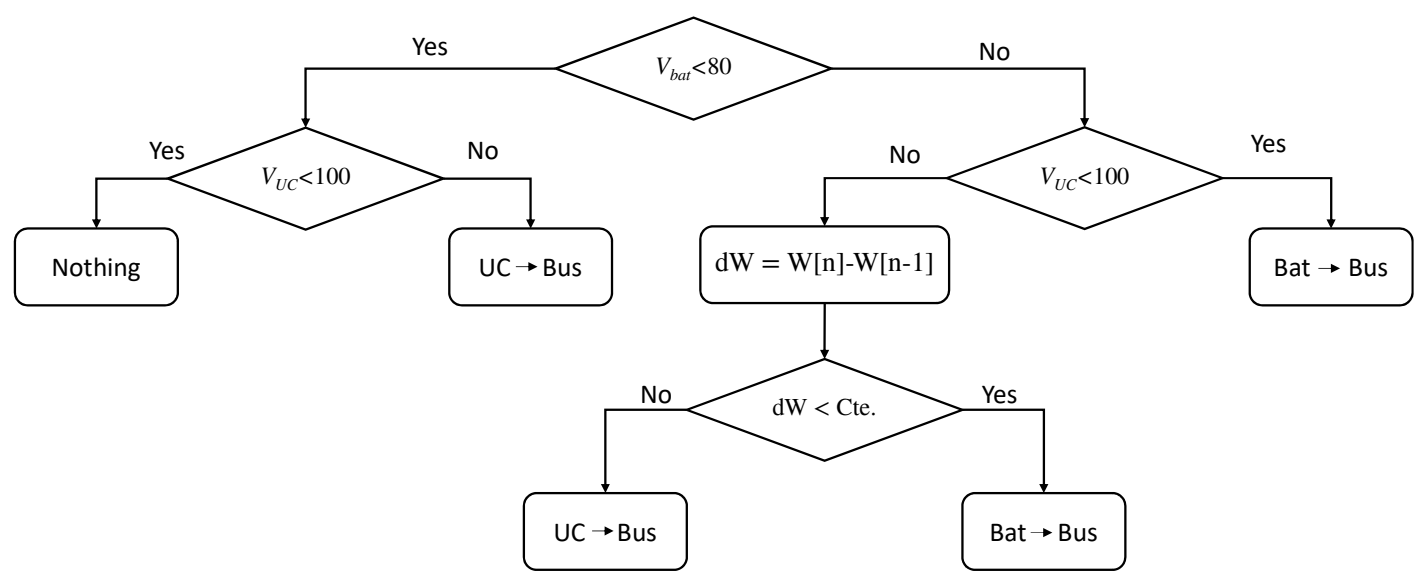

Figure 12. Flowchart followed by the EMS when the vehicle is in motion and there is energy in both power sources.

The control strategy previously presented requires a complement when it is required to interact with the grid. For this purpose, there are two well differentiated cases; charging the battery or the UC from the grid or injecting the energy generated in the PV into the grid. Figure 13 shows the block diagram for the charge of the storage elements. The objective is to regulate the current in the inductor $L_{2}$ and send it to the device that requires it. In Reference [58], it was proved that the SMC technique is adequate for achieving the control of an inverter interacting with the grid. For that reason this strategy was used and, in addition, it was necessary to know if the voltage grid is in the positive or negative half cycle to act on the necessary switch. Table 6 shows the behavior of the charge decoder. The switches that are not considered in Table 6 are kept off all the time. 


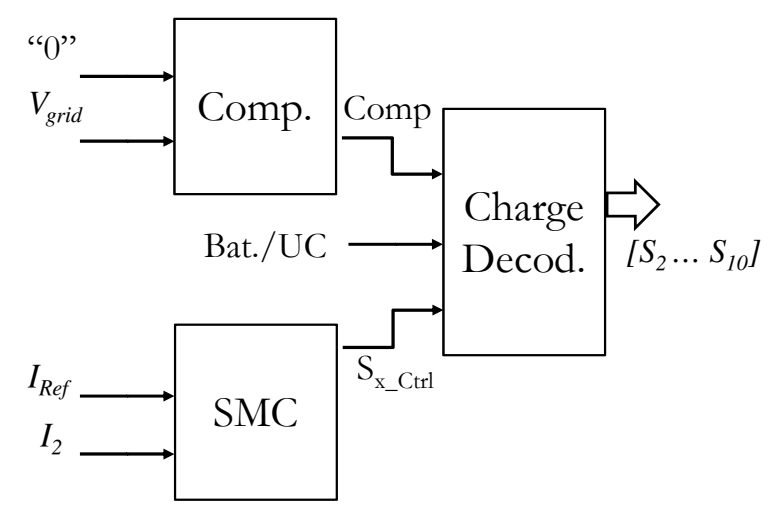

Figure 13. Block diagram of the control strategy of the charge from the grid.

Table 6. Behavior of the charge decoder.

\begin{tabular}{ccccccccc}
\hline Bat./UC & Comp & $S_{x_{-} \text {Ctrl }}$ & $S_{\mathbf{5}}$ & $S_{\boldsymbol{x}}$ & $S_{\boldsymbol{y}}$ & $S_{\mathbf{8}}$ & $S_{\mathbf{9}}$ & $S_{\mathbf{1 0}}$ \\
\hline 0 & 0 & 0 & 0 & 1 & 0 & 0 & 1 & 1 \\
0 & 0 & 1 & 1 & 0 & 0 & 0 & 1 & 1 \\
0 & 1 & 0 & 0 & 0 & 1 & 0 & 1 & 0 \\
0 & 1 & 1 & 0 & 0 & 1 & 0 & 1 & 0 \\
1 & 0 & 0 & 0 & 0 & 1 & 1 & 0 & 1 \\
1 & 0 & 1 & 1 & 0 & 0 & 0 & 1 & 1 \\
1 & 1 & 0 & 0 & 1 & 0 & 1 & 0 & 0 \\
1 & 1 & 1 & 0 & 1 & 0 & 1 & 0 & 0 \\
\hline
\end{tabular}

On the other hand, Figure 14 shows the block diagram for the injection of current into the grid. One of the objectives is to create a hysteresis behavior in the voltage $V_{p v}$ acting on the current $I_{2}$ reference. If the voltage increases above a set value, the reference is augmented in order to decrease the voltage below a permissible value where is increased the current reference again. It is necessary to maintain the voltage $V_{p v}$ above $170 \mathrm{~V}$ to guaranteed a satisfactory injection of the current into the grid. Moreover, in order to achieve an interaction with low THD at the beginning and at the end of the injection are executed in the zero-crossing. Finally, two separated SMC are implemented for each inductor $\left(I_{2}\right.$ and $\left.I_{g}\right)$. With this information and the half-cycle in which the grid is operating, the injection decoder establishes the corresponding signal in each inductor. Table 7 shows the behavior of the injection decoder. The switches that are not considered in Table 7 are kept off all the time.

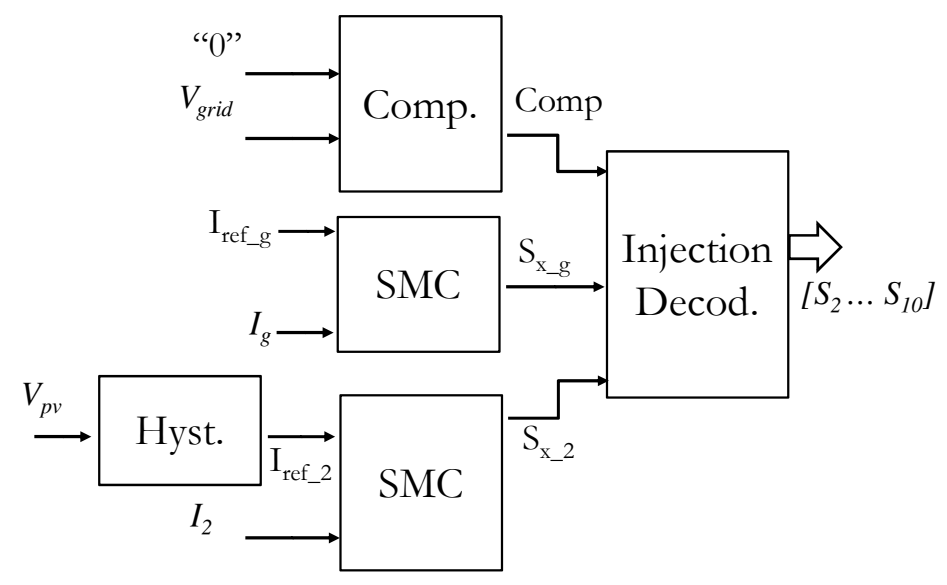

Figure 14. Block diagram of the control strategy of the injection of current into grid. 
Table 7. Behavior of the injection decoder.

\begin{tabular}{ccccccccc}
\hline Comp & $S_{x \_g}$ & $S_{x_{-} 2}$ & $S_{4}$ & $S_{5}$ & $S_{x}$ & $S_{y}$ & $S_{8}$ & $S_{g}$ \\
\hline 0 & 0 & 0 & 0 & 1 & 0 & 0 & 1 & 1 \\
0 & 0 & 1 & 1 & 0 & 0 & 0 & 1 & 1 \\
0 & 1 & 0 & 0 & 0 & 1 & 0 & 1 & 0 \\
0 & 1 & 1 & 0 & 0 & 1 & 0 & 1 & 0 \\
1 & 0 & 0 & 0 & 0 & 1 & 1 & 0 & 1 \\
1 & 0 & 1 & 1 & 0 & 0 & 0 & 1 & 1 \\
1 & 1 & 0 & 0 & 1 & 0 & 1 & 0 & 0 \\
1 & 1 & 1 & 0 & 1 & 0 & 1 & 0 & 0 \\
\hline
\end{tabular}

\section{Simulation Results}

The validation of the proposed converter and the control strategy was realized by the simulation of the system in the PSIM software (version 9.0.3). The main considerations for the simulation are presented in Table 8.

Table 8. Considerations for the simulation of the multiple-input converter.

\begin{tabular}{cc}
\hline Power Source & Sizing \\
\hline Battery & $100-144 \mathrm{~V}, 15 \mathrm{Ah}$ \\
UC & $125 \mathrm{~V}, 5 \mathrm{~F}$ \\
PV & $100-125 \mathrm{~W}$ \\
PMSM & $2.5 \mathrm{~kW}$ \\
Power converter & $3.5 \mathrm{~kW}$ \\
\hline
\end{tabular}

The validation of the blocks of MPPT was possible in a separate way. Figure 15a shows the MPPT achieved for the PV utilizing the multiple-input converter for this purpose. It can be appreciated that the system has a good response with this method. The settling time is less than $0.1 s$ for a power variation of $100 \mathrm{~W}$. Moreover, in steady-state, the ripple current is less than $0.25 \mathrm{~A}$ and the ripple power is less than $1 \mathrm{~W}$. Otherwise, the second method is manipulating the switches $S_{U C}$ and $S_{1}$, obtaining the response shown in Figure 15b. It is realized that this is a response of lesser quality. The settling time is of $0.02 \mathrm{~s}$ and in steady-state, there is a current ripple of $15 \mathrm{~A}$ and a power ripple of $8 \mathrm{~W}$. Despite the lesser quality response obtained with this method, it has the advantage that the multiple-input converter can be dedicated to other tasks.

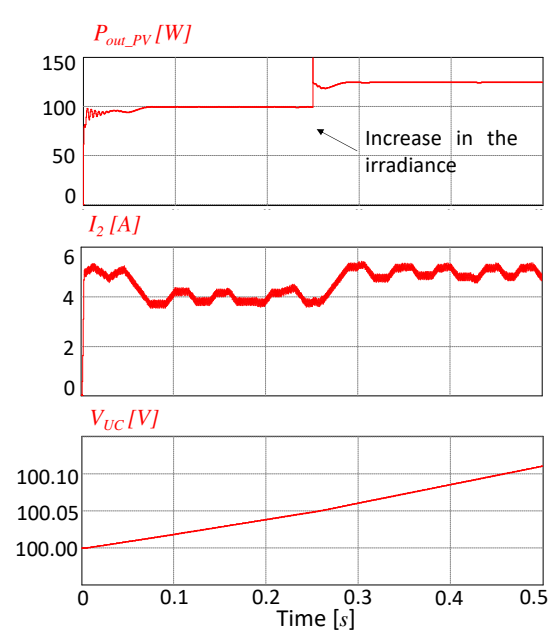

(a)

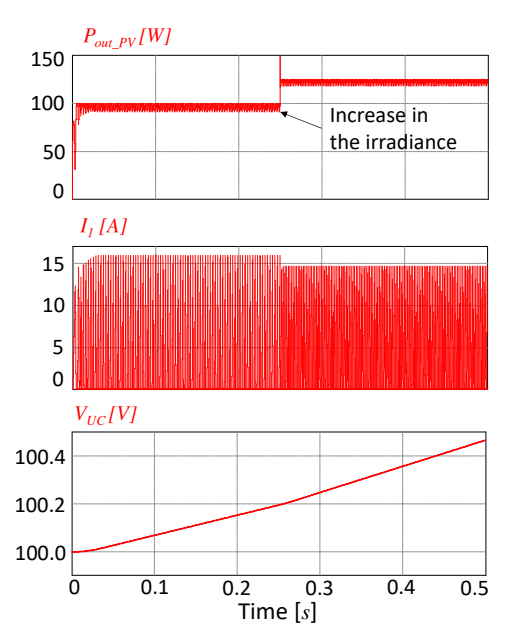

(b)

Figure 15. Methods implemented to achieve the MPPT of the PV, (a) utilizing the multiple-input converter and manipulating the reference of the current $I_{2},(\mathbf{b})$ manipulating the switches $S_{U C}$ and $S_{1}$. 
The PMSG also needs an MPPT algorithm for the harvesting of the energy. Figure 16 shows the simulation results for the implemented algorithm. It can be appreciated that by maintaining the voltage $V_{b u s}$ constant the MPPT is achieved. With a previous characterization of the electric machine it can be concluded that $92 \%$ and $97 \%$ of the possible total were extracted, respectively, for the conditions of the test.

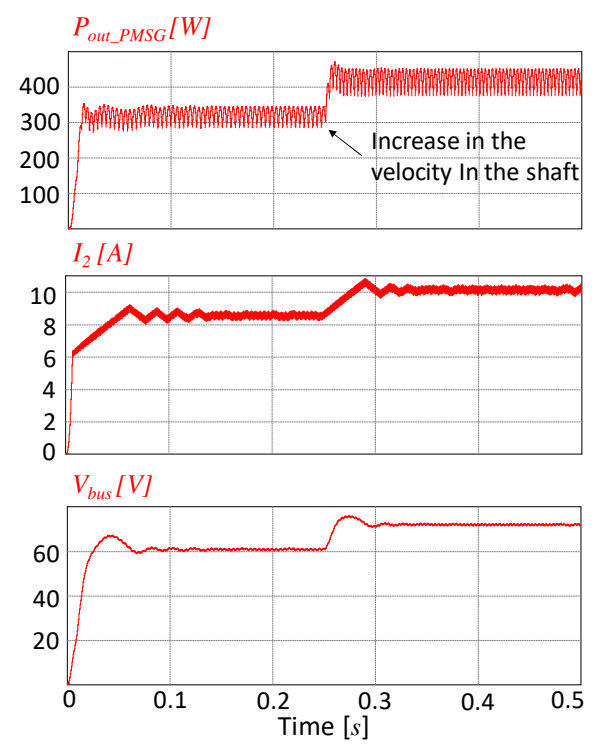

Figure 16. MPPT achieved in the PMSG by keeping the voltage in the capacitor $C_{b u s}$ constant.

For the validation of the EMS and the performance of the converter, the driving cycle ECE-15, which was legislated in the European Union in 1970, was utilized. Figure 17 shows the behavior of the state variables of the converter during the cycle. It can be concluded that the regulation of these variables was successful, with a ripple current of $0.8 \mathrm{~A}$ in steady-state and the desired hysteresis of $100 \mathrm{~V}$ for the voltage $V_{b u s}$. Figure 18 shows the performance of the power sources. It is important to point out that the UC supplies the energy during the velocity transitions and when the velocity remains relatively constant the demanded energy is supplied by the battery as desired. Finally, the behavior of the PV and the PMSG is shown in Figure 19. The PV is generating energy during the entire duration of the cycle and verifies the proper switch between the two methods implemented. The generation of energy from the pedals was simulated in the beginning of the cycle, obtaining the desired behavior of the system.

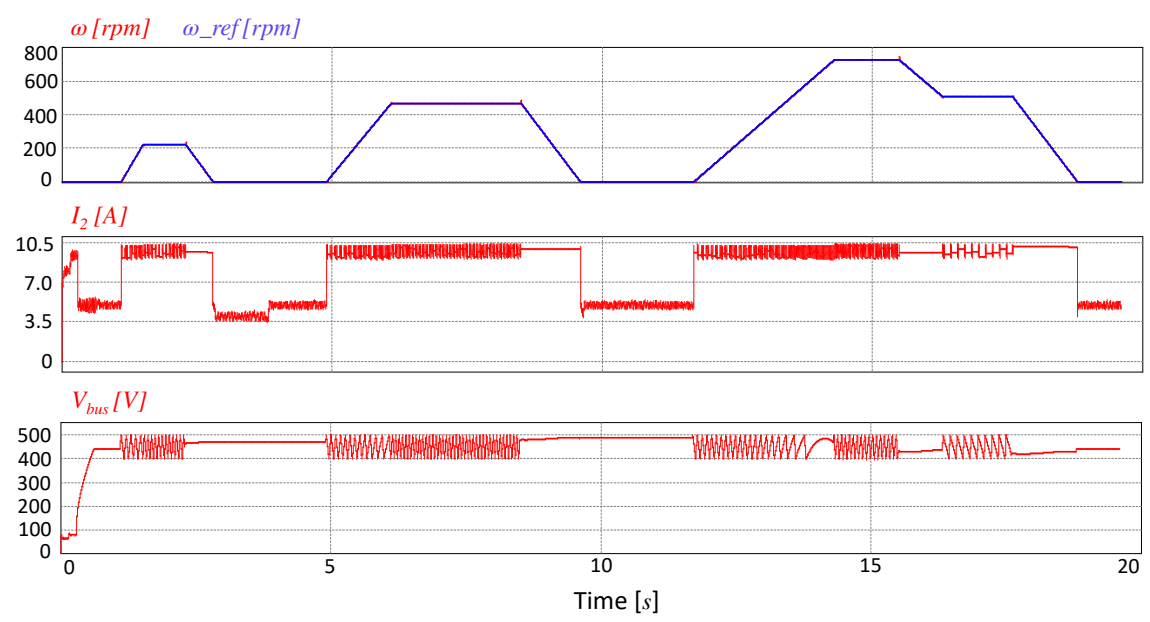

Figure 17. Behavior of the state variables through the ECE-15 cycle. The speed of the motor following the ECE-15 cycle; the current through inductor $L_{2}, I_{2}$ and the voltage in the capacitor $C_{b u s}, V_{b u s}$. 


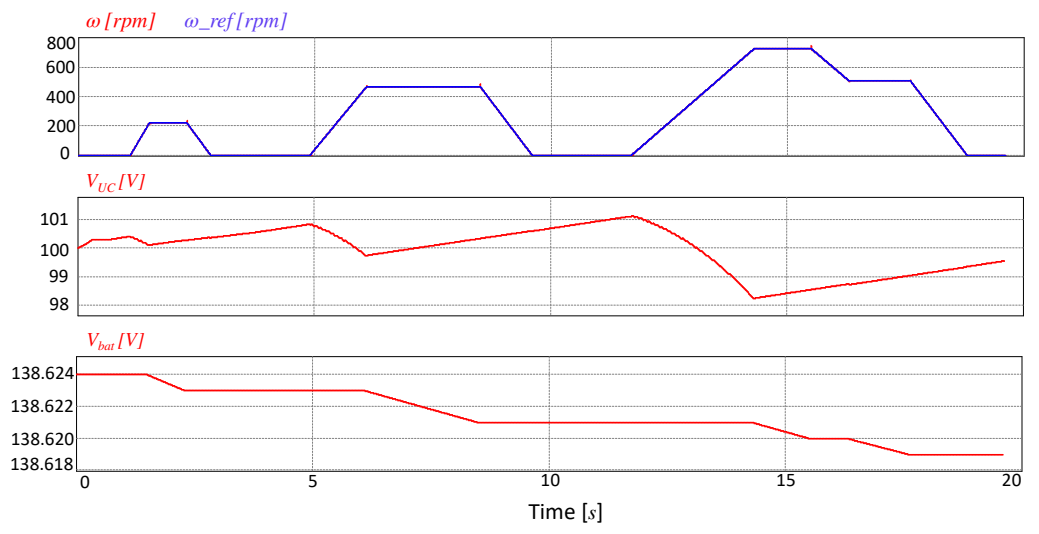

Figure 18. Behavior of the energy storage devices through the ECE-15 cycle. The speed of the motor following the ECE-15 cycle; the voltage in the ultracapacitor $V_{U C}$ and the voltage in the battery $V_{b a t}$.
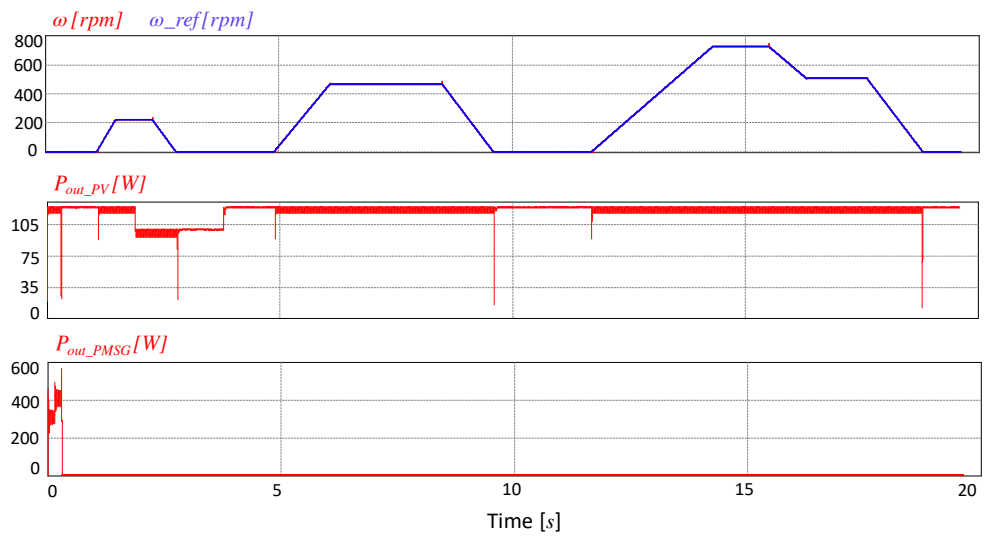

Figure 19. Behavior of the energy sources through the ECE-15 cycle. The speed of the motor following the ECE-15 cycle; the power harvested from the solar panel $P_{\text {out }} P V$ and the power harvested from the PMSG P Put_PMSG.

Finally, the interaction with the grid was validated. Figure 20 shows the charge of the battery. It can be appreciated that the battery has been charged and the current $I_{2}$ is regulated in $10 \mathrm{~A}$ with a ripple of $1 \mathrm{~A}$. Despite the main objective being achieved, the system presents a deficient power quality. In order to achieve a better response, a PFC strategy need to be implemented.
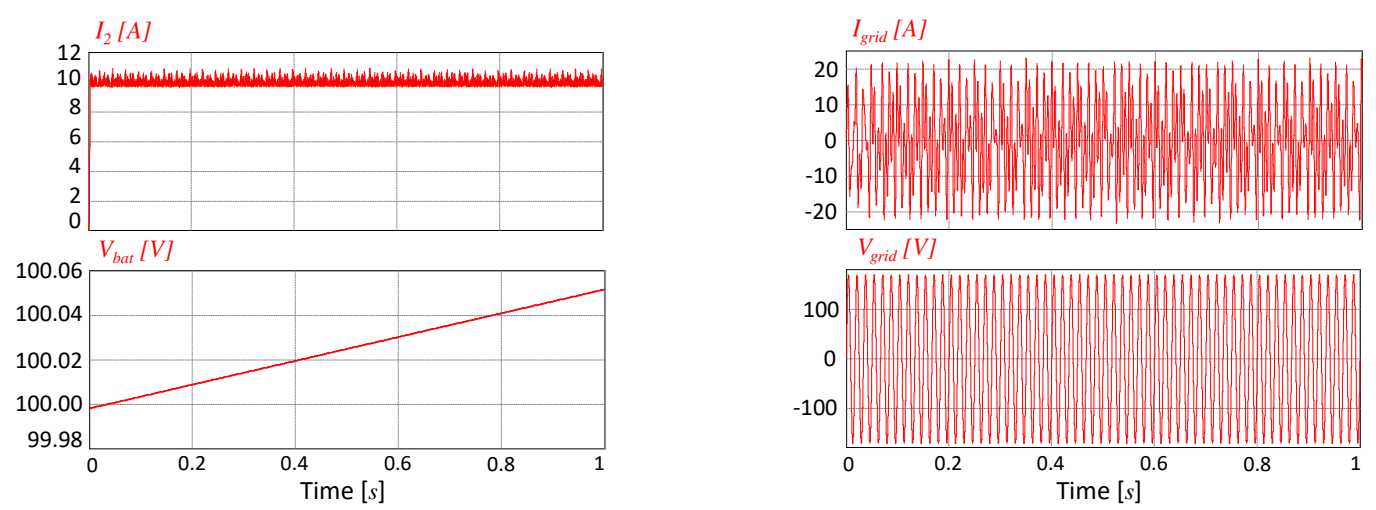

Figure 20. Charge of the battery from the grid: Current through the inductor $L_{2}, I_{2}$; voltage in the battery $V_{b a t}$; current in the grid $I_{\text {grid }}$ and the voltage in the grid $V_{\text {grid }}$.

Figure 21 demonstrates the injection of current into the grid. It can be appreciated that the MPPT is working properly as is the hysteresis of the voltage $V_{p v}$. This behavior of the voltage is permissible 
because the only restriction is that needs to be greater than $170 \mathrm{~V}$ and it is achieved by modifying the current amplitude injected into the grid. Figure 22 shows a zoom of the injected current where it can be appreciated that it is in phase with the normalized voltage grid and it is also notable that the start of the injection coincides with the zero-crossing.
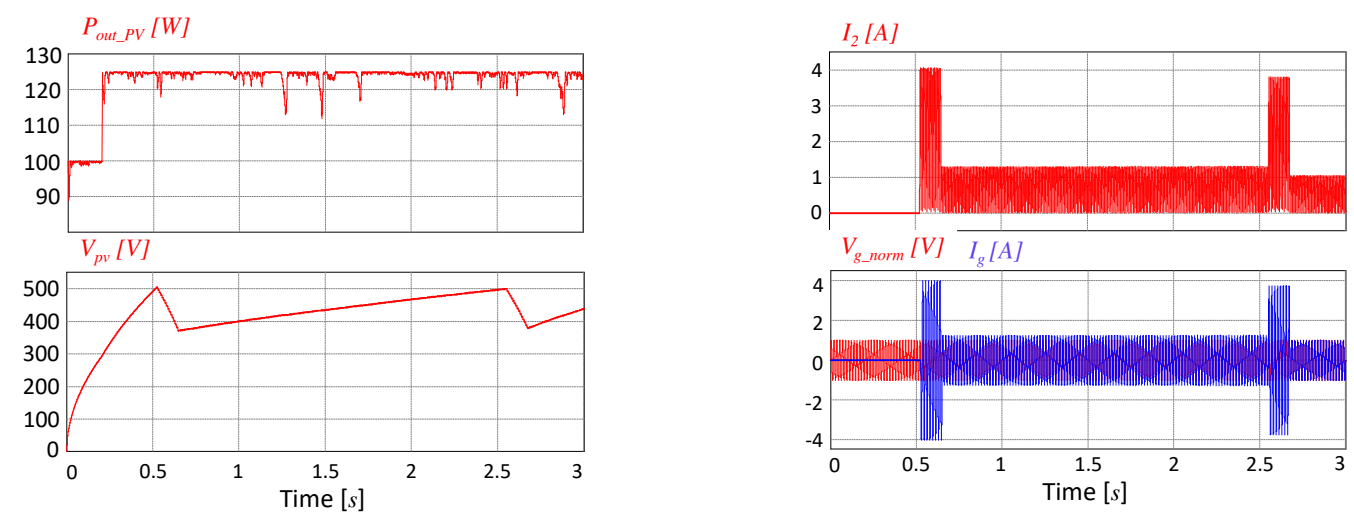

Figure 21. Injection of current into the grid-the power harvested from the solar panel $P_{\text {out_PV }}$; the voltage in the capacitor $C_{p v}, V_{p v}$; the current in the inductor $L_{2}, I_{2}$ and the voltage and current of the grid $V_{\text {grid }}$ and $I_{\text {grid }}$ respectively.

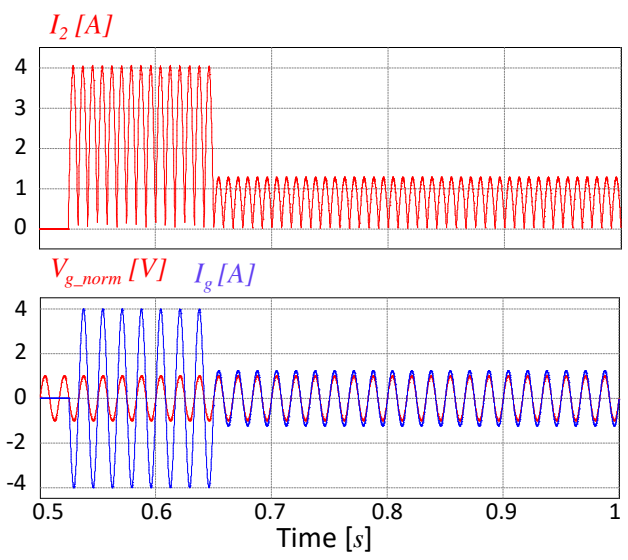

Figure 22. Zoom of the currents in the interval $0.5 s$ to $1 s$-the current in the inductor $L_{2}, I_{2}$ and the voltage and current of the grid $V_{\text {grid }}$ and $I_{\text {grid }}$ respectively.

\section{Conclusions}

In this work, a bidirectional multiple-input DC-DC converter topology is proposed for electric vehicles. A very flexible topology has been achieved, which gathers all the advantages identified in the converters presented in the literature. This converter allows the interaction of two or more energy sources with a wide range of voltage in its inputs with a direct current bus. It can be operated in buck or boost mode for each possible transfer. In addition, each element of the system can be a source or destination in a transfer. Moreover, it permits the direct transfer of energy between sources and it only presents a single inductor which will impact the weight of the vehicle. Finally, due to the arrangement of the switches, it can be said that it allows the interaction with the grid to charge the battery and UC and to deliver energy from these devices.

Likewise, a detailed analysis of the operation of the converter was presented in the operating modes of interest for the application. A control strategy based on different levels of hierarchy was implemented to achieve the proper performance of the system. The regulation of the current of the converter was achieved by an SMC, while the voltage was regulated with an on-off controller. The MPPT was realized in the PV using two different converters, based on the $\mathrm{P} \& \mathrm{O}$ algorithm. By using 
two converters it simplifies the control system. Meanwhile, the MPPT in the PMSG was accomplished by controlling the voltage on the capacitor of the direct current bus. In addition, an EMS was developed to decide the corresponding transfer at each time.

Because of its versatility, this converter is not only limited to its application in electric or hybrid vehicles. It can also be used in smart grids, microgrids, as a resource in distributed energy systems, battery charging management systems and so forth, in any application where the interaction of two or more sources is needed with the possibility of bidirectional power flow.

For future works the overall control system will be redesigned; an EMS based on fuzzy logic, which will increase the efficiency of the system and it will be more robust in situations that were not considered and a stability analysis will be developed. Moreover, a PFC strategy needs to be implemented for the charging of the power sources, and a control strategy that permit the boosting of the input voltage needs to be designed for the injection of current into the grid in order to be able to use the battery. Finally, experimental results that validate the system need to be performed, where it is assumed that the main constraints will be associated with the switching frequency in the current control loop of the $L_{2}$ inductor and in the transitions between the EMS states.

Author Contributions: Conceptualization, A.A.-D. and H.L.; methodology, A.A.-D., H.L. and R.V.C.-S.; software, A.A.-D., H.L. and N.V.; validation, A.A.-D., H.L., R.V.C.-S., J.R.-R. and N.V.; formal analysis, H.L., R.V.C.-S., J.R.-R. and N.V.; writing - original draft preparation, A.A.-D., H.L., R.V.C.-S. and J.R.-R.; writing—review and editing, G.H.-R.; supervision, R.V.C.-S., J.R.-R. and N.V.

Funding: This research was funded by the "Consejo Nacional de Ciencia y Tecnología (CONACYT)".

Conflicts of Interest: The authors declare no conflict of interest.

\section{References}

1. Solaymani, $\mathrm{S} . \mathrm{CO}_{2}$ emissions patterns in 7 top carbon emitter economies: The case of transport sector. Energy 2019, 168, 989-1001. [CrossRef]

2. Khaligh, A.; Li, Z. Battery, ultracapacitor, fuel cell, and hybrid energy storage systems for electric, hybrid electric, fuel cell, and plug-in hybrid electric vehicles: State of the art. IEEE Trans. Veh. Technol. 2010, 59, 2806-2814. [CrossRef]

3. Dusmez, S.; Hasanzadeh, A.; Khaligh, A. Comparative analysis of bidirectional three-level DC-DC converter for automotive applications. IEEE Trans. Ind. Electron. 2014, 62, 3305-3315. [CrossRef]

4. Shen, J.; Dusmez, S.; Khaligh, A. Optimization of sizing and battery cycle life in battery/ultracapacitor hybrid energy storage systems for electric vehicle applications. IEEE Trans. Ind. Inform. 2014, 10, 2112-2121. [CrossRef]

5. Lu, S.; Corzine, K.A.; Ferdowsi, M. A new battery/ultracapacitor energy storage system design and its motor drive integration for hybrid electric vehicles. IEEE Trans. Veh. Technol. 2007, 56, 1516-1523. [CrossRef]

6. Dusmez, S.; Khaligh, A. A supervisory power-splitting approach for a new ultracapacitor-battery vehicle deploying two propulsion machines. IEEE Trans. Ind. Inform. 2014, 10, 1960-1971. [CrossRef]

7. Emadi, A.; Williamson, S. Fuel cell vehicles: Opportunities and challenges. In Proceedings of the IEEE Power Engineering Society General Meeting, Denver, CO, USA, 6-10 June 2004; pp. 1640-1645.

8. Aso, S.; Kizaki, M.; Nonobe, Y. Development of fuel cell hybrid vehicles in Toyota. In Proceedings of the 2007 Power Conversion Conference-Nagoya, Nagoya, Japan, 2-5 April 2007; pp. 1606-1611.

9. Rajashekara, K. Present status and future trends in electric vehicle propulsion technologies. IEEE J. Emerg. Sel. Top. Power Electron. 2013, 1, 3-10. [CrossRef]

10. Ding, Z.; Yang, C.; Zhang, Z.; Wang, C.; Xie, S. A novel soft-switching multiport bidirectional DC-DC converter for hybrid energy storage system. IEEE Trans. Power Electron. 2013, 29, 1595-1609. [CrossRef]

11. Dusmez, S.; Li, X.; Akin, B. A new multiinput three-level DC-DC converter. IEEE Trans. Power Electron. 2015, 31, 1230-1240. [CrossRef]

12. Reddi, N.; Ramteke, M.; Suryawanshi, H. Dual-Input Single-Output Isolated Resonant Converter with Zero Voltage Switching. Electronics 2018, 7, 96. [CrossRef]

13. Lu, S.; Corzine, K.A.; Ferdowsi, M. A unique ultracapacitor direct integration scheme in multilevel motor drives for large vehicle propulsion. IEEE Trans. Veh. Technol. 2007, 56, 1506-1515. [CrossRef] 
14. Camara, M.B.; Gualous, H.; Gustin, F.; Berthon, A.; Dakyo, B. DC-DC converter design for supercapacitor and battery power management in hybrid vehicle applications-Polynomial control strategy. IEEE Trans. Ind. Electron. 2009, 57, 587-597. [CrossRef]

15. Kollimalla, S.K.; Mishra, M.K.; Narasamma, N.L. Design and analysis of novel control strategy for battery and supercapacitor storage system. IEEE Trans. Sustain. Energy 2014, 5, 1137-1144. [CrossRef]

16. Tani, A.; Camara, M.B.; Dakyo, B. Energy management based on frequency approach for hybrid electric vehicle applications: Fuel-cell/lithium-battery and ultracapacitors. IEEE Trans. Veh. Technol. 2012, 61, 3375-3386. [CrossRef]

17. Zandi, M.; Payman, A.; Martin, J.P.; Pierfederici, S.; Davat, B.; Meibody-Tabar, F. Energy management of a fuel cell/supercapacitor/battery power source for electric vehicular applications. IEEE Trans. Veh. Technol. 2010, 60, 433-443. [CrossRef]

18. Payman, A.; Pierfederici, S.; Meibody-Tabar, F.; Davat, B. An adapted control strategy to minimize DC-bus capacitors of a parallel fuel cell/ultracapacitor hybrid system. IEEE Trans. Power Electron. 2009, 26, 3843-3852. [CrossRef]

19. Nejabatkhah, F.; Danyali, S.; Hosseini, S.H.; Sabahi, M.; Niapour, S.M. Modeling and control of a new three-input DC-DC boost converter for hybrid PV/FC/battery power system. IEEE Trans. Power Electron. 2011, 27, 2309-2324. [CrossRef]

20. Khaligh, A. A multiple-input DC-DC positive buck-boost converter topology. In Proceedings of the 2008 Twenty-Third Annual IEEE Applied Power Electronics Conference and Exposition, Austin, TX, USA, 24-28 February 2008; pp. 1522-1526.

21. Peng, F.Z.; Shen, M.; Holland, K. Application of Z-source inverter for traction drive of fuel cell-Battery hybrid electric vehicles. IEEE Trans. Power Electron. 2007, 22, 1054-1061. [CrossRef]

22. Solero, L.; Lidozzi, A.; Pomilio, J.A. Design of multiple-input power converter for hybrid vehicles. IEEE Trans. Power Electron. 2005, 20, 1007-1016. [CrossRef]

23. Akar, F.; Tavlasoglu, Y.; Ugur, E.; Vural, B.; Aksoy, I. A bidirectional nonisolated multi-input DC-DC converter for hybrid energy storage systems in electric vehicles. IEEE Trans. Veh. Technol. 2015, 65, 7944-7955. [CrossRef]

24. Hintz, A.; Prasanna, U.R.; Rajashekara, K. Novel modular multiple-input bidirectional DC-DC power converter (MIPC) for HEV/FCV application. IEEE Trans. Ind. Electron. 2014, 62, 3163-3172. [CrossRef]

25. Ahrabi, R.R.; Ardi, H.; Elmi, M.; Ajami, A. A novel step-up multiinput DC-DC converter for hybrid electric vehicles application. IEEE Trans. Power Electron. 2016, 32, 3549-3561. [CrossRef]

26. Babaei, E.; Abbasi, O. Structure for multi-input multi-output DC-DC boost converter. IET Power Electron. 2016, 9, 9-19. [CrossRef]

27. Nahavandi, A.; Hagh, M.T.; Sharifian, M.B.B.; Danyali, S. A nonisolated multiinput multioutput DC-DC boost converter for electric vehicle applications. IEEE Trans. Power Electron. 2014, 30, 1818-1835. [CrossRef]

28. López, H.; Rodríguez-Reséndiz, J.; Guo, X.; Vázquez, N.; Carrillo-Serrano, R.V. Transformerless common-mode current-source inverter grid-connected for PV applications. IEEE Access 2018, 6, 62944-62953. [CrossRef]

29. Zsiborács, H.; Hegedúsné Baranyai, N.; Csányi, S.; Vincze, A.; Pintér, G. Economic Analysis of Grid-Connected PV System Regulations: A Hungarian Case Study. Electronics 2019, 8, 149. [CrossRef]

30. Mali, V.D.; Thorat, A.; Sawant, N.K. An Isolated Multiport Bidirectional DC-DC Converter for PV Battery System. In Proceedings of the 2018 Second International Conference on Inventive Communication and Computational Technologies (ICICCT), Coimbatore, India, 20-21 April 2018; pp. 302-306.

31. Khatab, A.M.; Marei, M.I.; Elhelw, H.M. An Electric Vehicle Battery Charger Based on Zeta Converter Fed from a PV Array. In Proceedings of the 2018 IEEE International Conference on Environment and Electrical Engineering and 2018 IEEE Industrial and Commercial Power Systems Europe (EEEIC/I\&CPS Europe), Palermo, Italy, 12-15 June 2018; pp. 1-5.

32. Chen, X.; Pise, A.A.; Elmes, J.; Batarseh, I. Ultra-Highly Efficient Low Power Bi-directional Cascaded-Buck-Boost Converter for Portable PV-Battery-Devices Applications. IEEE Trans. Ind. Appl. 2019, 55, 3989-4000. [CrossRef]

33. Liu, S.; Gao, Y.; Yang, L. Research on Application of Non-Isolated Three-Port Switching Boost Converter in Photovoltaic Power Generation System. Electronics 2019, 8, 746. [CrossRef]

34. Chewale, M.A.; Wanjari, R.A.; Savakhande, V.B.; Sonawane, P.R. A Review on Isolated and Non-isolated DC-DC Converter for PV Application. In Proceedings of the 2018 International Conference on Control, Power, Communication and Computing Technologies (ICCPCCT), Kannur, India, 23-24 March 2018; pp. 399-404. 
35. Fahem, K.; Chariag, D.E.; Sbita, L. On-board bidirectional battery chargers topologies for plug-in hybrid electric vehicles. In Proceedings of the 2017 International Conference on Green Energy Conversion Systems (GECS), Hammamet, Tunisia, 23-25 March 2017; pp. 1-6.

36. Rippel, W.E. Integrated Traction Inverter and Battery Charger Apparatus. U.S. Patent 4,920,475, 24 April 1990.

37. Rippel, W.E.; Cocconi, A.G. Integrated Motor Drive and Recharge System. U.S. Patent 5,099,186, 24 March 1992.

38. Cocconi, A.G. Combined Motor Drive and Battery Recharge System. U.S. Patent 5,341,075, 23 August 1994.

39. Sul, S.K.; Lee, S.J. An integral battery charger for four-wheel drive electric vehicle. IEEE Trans. Ind. Appl. 1995, 31, 1096-1099.

40. Hegazy, O.; Van Mierlo, J.; Lataire, P. Design and control of bidirectional DC/AC and DC/DC converters for plug-in hybrid electric vehicles. In Proceedings of the 2011 International Conference on Power Engineering, Energy and Electrical Drives, Malaga, Spain, 11-13 May 2011; pp. 1-7.

41. De Sousa, L.; Silvestre, B.; Bouchez, B. A combined multiphase electric drive and fast battery charger for electric vehicles. In Proceedings of the 2010 IEEE Vehicle Power and Propulsion Conference, Lille, France, 1-3 September 2010; pp. 1-6.

42. Lacroix, S.; Labouré, E.; Hilairet, M. An integrated fast battery charger for electric vehicle. In Proceedings of the 2010 IEEE Vehicle Power and Propulsion Conference, Lille, France, 1-3 September 2010; pp. 1-6.

43. Haghbin, S.; Lundmark, S.; Alakula, M.; Carlson, O. An isolated high-power integrated charger in electrified-vehicle applications. IEEE Trans. Veh. Technol. 2011, 60, 4115-4126. [CrossRef]

44. Subotic, I.; Levi, E. An integrated battery charger for EVs based on a symmetrical six-phase machine. In Proceedings of the 2014 IEEE 23rd International Symposium on Ind. Electron (ISIE), Istanbul, Turkey, 1-4 June 2014; pp. 2074-2079.

45. Lee, Y.J.; Khaligh, A.; Emadi, A. Advanced integrated bidirectional AC/DC and DC/DC converter for plug-in hybrid electric vehicles. IEEE Trans. Veh. Technol. 2009, 58, 3970-3980.

46. Chen, H.; Wang, X.; Khaligh, A. A single stage integrated bidirectional ac/dc and dc/dc converter for plug-in hybrid electric vehicles. In Proceedings of the 2011 IEEE Vehicle Power and Propulsion Conference, Chicago, IL, USA, 6-9 September 2011; pp. 1-6.

47. Erb, D.C.; Onar, O.C.; Khaligh, A. An integrated bi-directional power electronic converter with multi-level AC-DC/DC-AC converter and non-inverted buck-boost converter for PHEVs with minimal grid level disruptions. In Proceedings of the 2010 IEEE Vehicle Power and Propulsion Conference, Lille, France, 1-3 September 2010; pp. 1-6.

48. Kumar, G.; Sarojini, R.K.; Palanisamy, K.; Sanjeevikumar, P.; Holm-Nielsen, J.B. Large Scale Renewable Energy Integration: Issues and Solutions. Energies 2019, 12, 1996. [CrossRef]

49. Mudhol, A.; Pius, P. Design and implementation of boost converter for photovoltaic systems. Int. J. Innov. Res. Elect. Electron. Instrum. Control Eng. 2016, 4, 110-114. [CrossRef]

50. Hauke, B. Basic Calculation of Buck Converter's Power Stages; Technical report, Texas, Tech. Rep. SLVA477, Dec; Texas Instruments: Dallas, TX, USA, 2011.

51. Hauke, B. Application Report: Basic Calculation of a Boost Converter's Power Stage; Texas Instruments: Dallas, TX, USA, 2014.

52. Abbas, G.; Gu, J.; Farooq, U.; Abid, M.; Raza, A.; Asad, M.; Balas, V.; Balas, M. Optimized Digital Controllers for Switching-Mode DC-DC Step-Down Converter. Electronics 2018, 7, 412. [CrossRef]

53. Sira-Ramirez, H.J.; Silva-Ortigoza, R. Control Design Techniques in Power Electronics Devices; Springer-Verlag: London, UK, 2006.

54. Yang, Y.; Tan, S.C. Trends and Development of Sliding Mode Control Applications for Renewable Energy Systems. Energies 2019, 12, 2861. [CrossRef]

55. Cucuzzella, M.; Rosti, S.; Cavallo, A.; Ferrara, A. Decentralized sliding mode voltage control in DC microgrids. In Proceedings of the 2017 American Control Conference (ACC), Seattle, WA, USA, 24-26 May 2017; pp. 3445-3450. 
56. Cucuzzella, M.; Lazzari, R.; Trip, S.; Rosti, S.; Sandroni, C.; Ferrara, A. Sliding mode voltage control of boost converters in DC microgrids. Control Eng. Pract. 2018, 73, 161-170. [CrossRef]

57. Kim, S.K.; Lee, K.B. Robust DC-Link Voltage Tracking Controller with Variable Control Gain for Permanent Magnet Synchronous Generators. Electronics 2018, 7, 339. [CrossRef]

58. Senthilnathan, K.; Annapoorani, I. Multi-port current source inverter for smart microgrid applications: A cyber physical paradigm. Electronics 2019, 8, 1. [CrossRef]

(C) 2019 by the authors. Licensee MDPI, Basel, Switzerland. This article is an open access article distributed under the terms and conditions of the Creative Commons Attribution (CC BY) license (http:/ / creativecommons.org/licenses/by/4.0/). 